Prepared in cooperation with the City of Albuquerque

\title{
Comparison of Storm Runoff Models for a Small Watershed in an Urban Metropolitan Area, Albuquerque, New Mexico
}

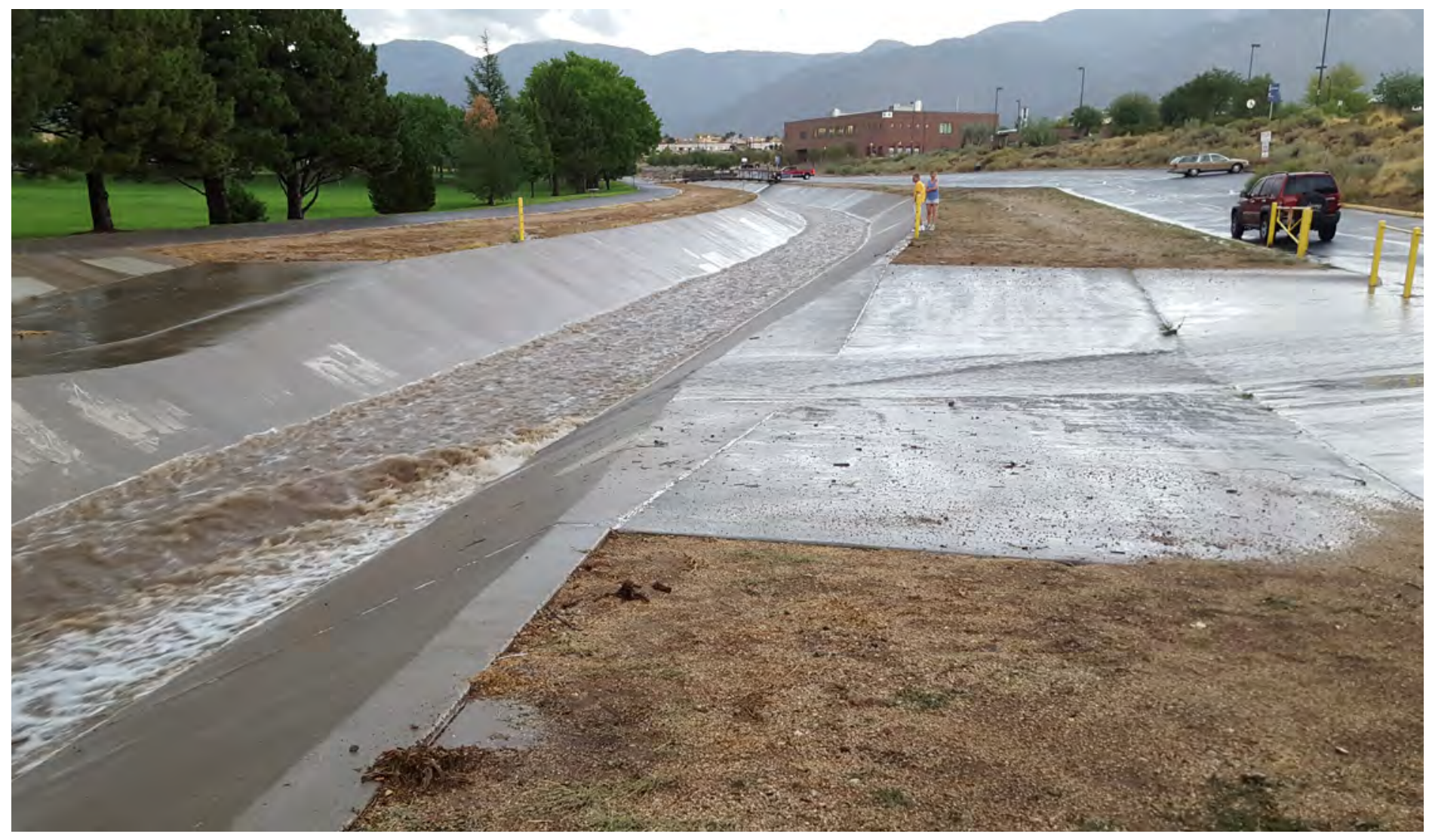

Scientific Investigations Report 2020-5058 
Cover. Photograph showing storm runoff in a concrete-lined channel in Albuquerque, New Mexico, July 14, 2018. 


\section{Comparison of Storm Runoff Models for a Small Watershed in an Urban Metropolitan Area, Albuquerque, New Mexico}

By Zachary M. Shephard and Kyle R. Douglas-Mankin

Prepared in cooperation with the City of Albuquerque

Scientific Investigations Report 2020-5058 


\title{
U.S. Department of the Interior \\ DAVID BERNHARDT, Secretary
}

\author{
U.S. Geological Survey \\ James F. Reilly II, Director
}

U.S. Geological Survey, Reston, Virginia: 2020

For more information on the USGS - the Federal source for science about the Earth, its natural and living resources, natural hazards, and the environment—visit https://www.usgs.gov or call 1-888-ASK-USGS.

For an overview of USGS information products, including maps, imagery, and publications, visit https://store.usgs.gov/.

Any use of trade, firm, or product names is for descriptive purposes only and does not imply endorsement by the U.S. Government.

Although this information product, for the most part, is in the public domain, it also may contain copyrighted materials as noted in the text. Permission to reproduce copyrighted items must be secured from the copyright owner.

Suggested citation:

Shephard, Z.M., and Douglas-Mankin, K.R., 2020, Comparison of storm runoff models for a small watershed in an urban metropolitan area, Albuquerque, New Mexico: U.S. Geological Survey Scientific Investigations Report 2020-5058, 30 p., https://doi.org/10.3133/sir20205058.

ISSN 2328-0328 (online) 


\section{Acknowledgments}

The authors thank Sertil Kanbar of the City of Albuquerque for providing geospatial data that were not readily available.

The authors also thank Orlando Romero, formerly of the U.S. Geological Survey, for the initial scoping and vision of the study, and Stephanie Roussel of the U.S. Geological Survey for reviewing discharge data and rating curves used in this study. 



\section{Contents}

Acknowledgments ……...................................................................................................................

Abstract

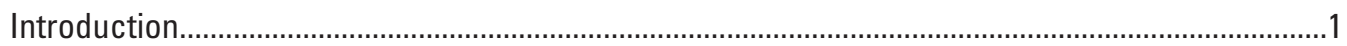

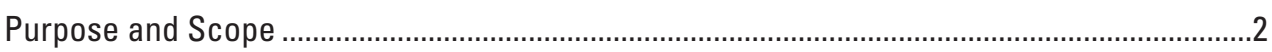

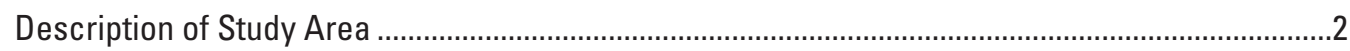

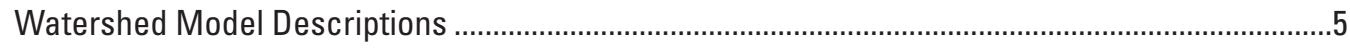

Hydrologic Engineering Center Hydrologic Modeling System (HEC-HMS) .............................5

Program for Predicting Polluting Particle Passage Through Pits, Puddles, and

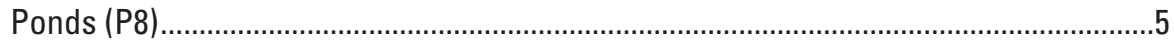

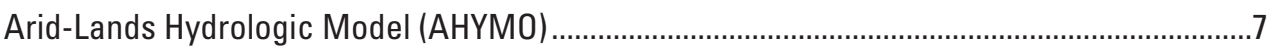

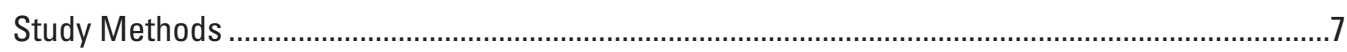

Watershed Delineation .......................................................................................................

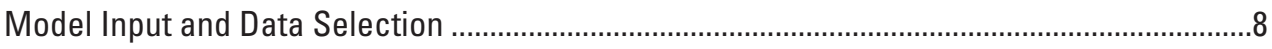

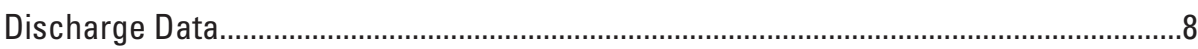

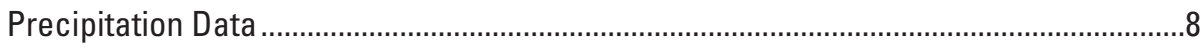

Soils, Land-Use, Elevation, and Other Watershed Data ....................................................

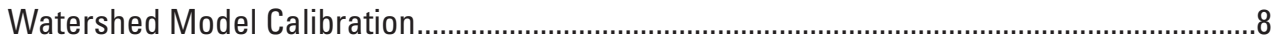

Calibration Strategy

Calibration Parameters ............................................................................................. 9

Model Performance Assessment and Model Validation ........................................................

Model Data Requirement Comparison ........................................................................................

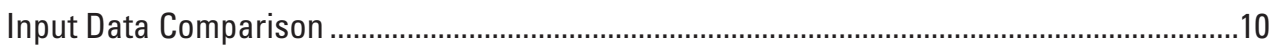

User Interface and Model Setup ..........................................................................................11

Model Process Assessment and Model Limitations ...................................................................12

Model Performance Assessment ............................................................................................12

Hydrologic Engineering Center Hydrologic Modeling System (HEC-HMS) ............................15

Curve Number Approach..............................................................................................15

Initial and Constant Approach .........................................................................................17

Program for Predicting Polluting Particle Passage Through Pits, Puddles, and

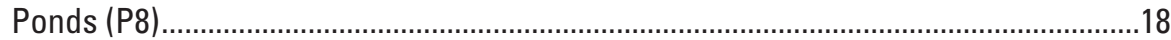

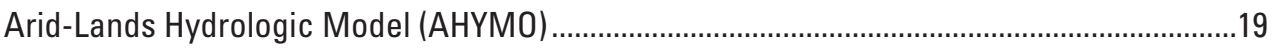

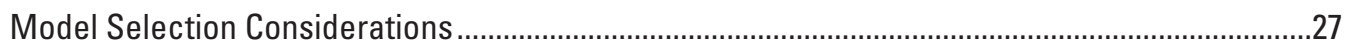

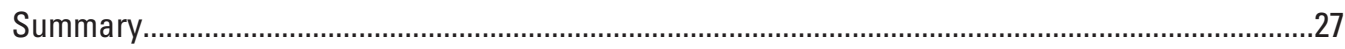

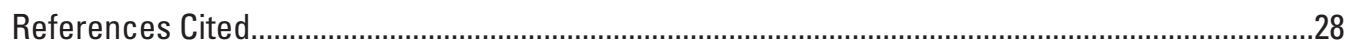

\section{Figures}

1. Map showing the location of the study watershed, the Hahn Arroyo watershed in Albuquerque, New Mexico

2. Graphs showing discharge data observed at the Hahn Arroyo streamgage and simulated by using the Hydrologic Engineering Center Hydrologic Modeling System curve-number approach during the calibration period and validation period 
3. Graphs showing discharge data observed at the Hahn Arroyo streamgage and simulated by using the Hydrologic Engineering Center Hydrologic Modeling System initial and constant loss approach during the calibration period and validation period

4. Graphs showing discharge data observed at the Hahn Arroyo streamgage and simulated by using the Program for Predicting Polluting Particle Passage through Pits, Puddles, and Ponds model during the calibration period and validation period

5. Graphs showing discharge data observed at the Hahn Arroyo streamgage and simulated by using the Arid-Lands Hydrologic Model for five rainfall-runoff events .....25

\section{Tables}

1. Characteristics and input requirements for the HEC-HMS, P8, and AHYMO models, specific to their usage in this study.

2. Initial parameter values and ranges, as well as the optimized parameter values and parameter sensitivities for the HEC-HMS curve-number-based model calibration process.

3. Initial parameter values and ranges, as well as the optimized parameter values and parameter sensitivities for the HEC-HMS initial and constant infiltration-based model calibration process.

4. Initial parameter values and ranges, as well as the optimized parameter values and parameter sensitivities for the P8 model calibration process.

5. Calibration period model performance measures, performance evaluation criteria, and relative model rank for HEC-HMS and P8 models.

6. Validation period model performance measures, performance evaluation criteria, and relative model rank for HEC-HMS and P8 models.

7. Summarized model performance measures rankings for HEC-HMS and P8 models ....17

8. Summarized model performance measures for the AHYMO model .............................19

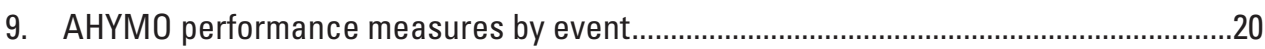




\section{Conversion Factors}

U.S. customary units to International System of Units

\begin{tabular}{|c|c|c|}
\hline Multiply & By & To obtain \\
\hline \multicolumn{3}{|c|}{ Length } \\
\hline inch (in.) & 2.54 & centimeter $(\mathrm{cm})$ \\
\hline inch (in.) & 25.4 & millimeter (mm) \\
\hline foot (ft) & 0.3048 & meter (m) \\
\hline mile (mi) & 1.609 & kilometer (km) \\
\hline \multicolumn{3}{|c|}{ Area } \\
\hline acre & 4,047 & square meter $\left(\mathrm{m}^{2}\right)$ \\
\hline acre & 0.4047 & hectare (ha) \\
\hline acre & 0.4047 & square hectometer $\left(\mathrm{hm}^{2}\right)$ \\
\hline acre & 0.004047 & square kilometer $\left(\mathrm{km}^{2}\right)$ \\
\hline square mile $\left(\mathrm{mi}^{2}\right)$ & 259.0 & hectare (ha) \\
\hline square mile $\left(\mathrm{mi}^{2}\right)$ & 2.590 & square kilometer $\left(\mathrm{km}^{2}\right)$ \\
\hline \multicolumn{3}{|c|}{ Volume } \\
\hline cubic foot $\left(\mathrm{ft}^{3}\right)$ & 28.32 & cubic decimeter $\left(\mathrm{dm}^{3}\right)$ \\
\hline cubic foot $\left(\mathrm{ft}^{3}\right)$ & 0.02832 & cubic meter $\left(\mathrm{m}^{3}\right)$ \\
\hline acre-foot (acre-ft) & 1,233 & cubic meter $\left(\mathrm{m}^{3}\right)$ \\
\hline acre-foot (acre-ft) & 0.001233 & cubic hectometer $\left(\mathrm{hm}^{3}\right)$ \\
\hline \multicolumn{3}{|c|}{ Flow rate } \\
\hline inch per hour (in/h) & 0.0254 & meter per hour $(\mathrm{m} / \mathrm{h})$ \\
\hline cubic foot per second $(\mathrm{ft} 3 / \mathrm{s})$ & 0.02832 & cubic meter per second $\left(\mathrm{m}^{3} / \mathrm{s}\right)$ \\
\hline
\end{tabular}

\section{Datum}

Vertical coordinate information is referenced to the North American Vertical Datum of 1988 (NAVD 88).

Horizontal coordinate information is referenced to the North American Datum of 1983 (NAD 83).

Elevation, as used in this report, refers to distance above the vertical datum. 


\section{Abbreviations}

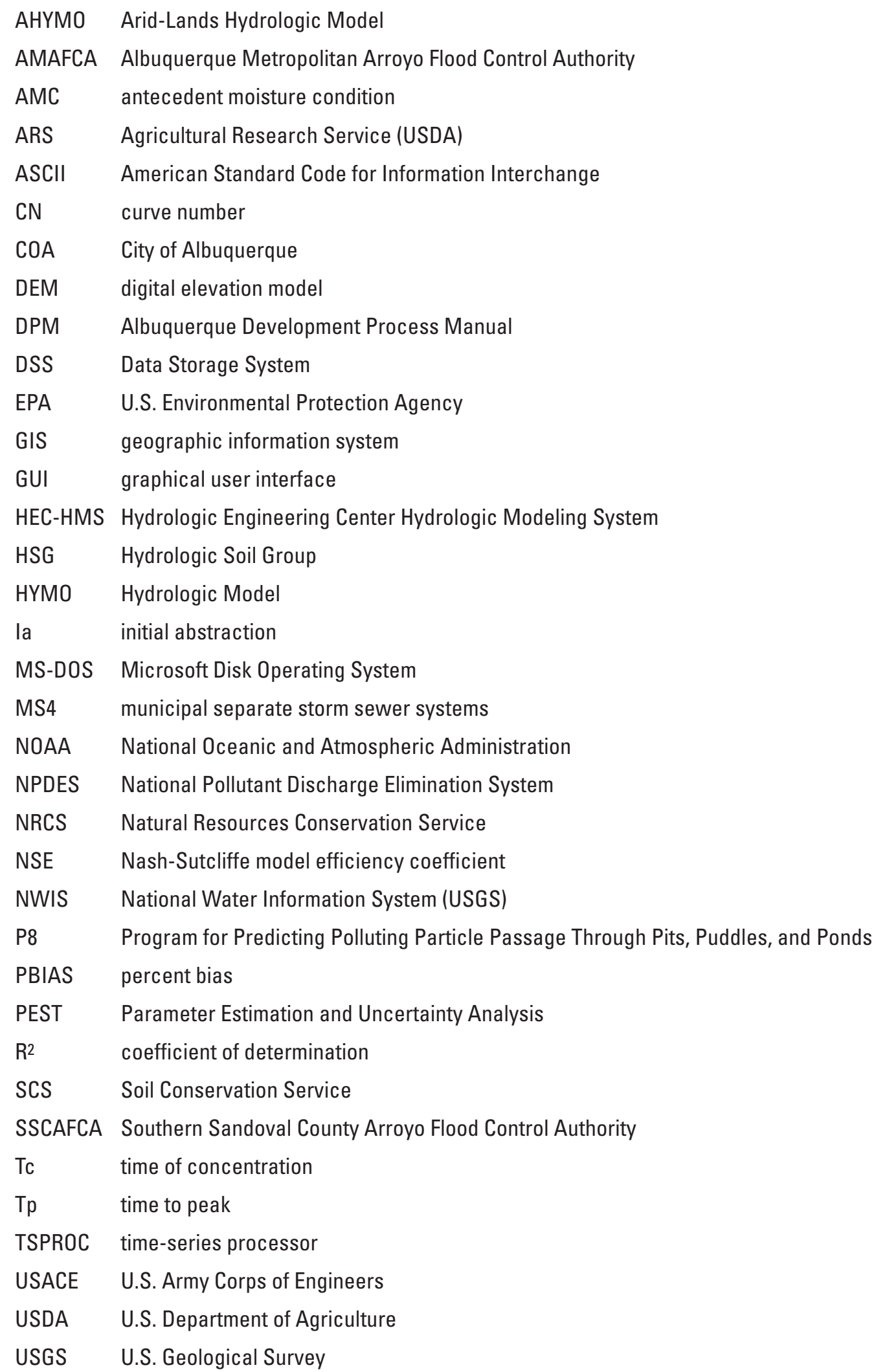




\title{
Comparison of Storm Runoff Models for a Small Watershed in an Urban Metropolitan Area, Albuquerque, New Mexico
}

\author{
By Zachary M. Shephard ${ }^{1}$ and Kyle R. Douglas-Mankin²
}

\section{Abstract}

In order to comply with a current U.S. Environmental Protection Agency watershed-based National Pollutant Discharge Elimination System permit, the City of Albuquerque required a better understanding of the rainfall-runoff processes in its small urban watersheds. That requirement prompted the initiation of the assessment of three existing watershed models that were developed to simulate those processes. Three existing rainfall-runoff modeling software packages - Hydrologic Engineering Center Hydrologic Modeling System (HECHMS) (using two sets of methods), Program for Predicting Polluting Particle Passage Through Pits, Puddles, and Ponds (P8), and Arid-Lands Hydrologic Model (AHYMO) — were compared to determine which provided the best balance of accuracy and usability for simulating storm runoff in small watersheds in the urbanized area of Albuquerque, New Mexico. Additionally, results of this study could help inform model users who have interest in simulating storm runoff in similar urban areas throughout the United States. Each model was used to simulate storm runoff in the Hahn Arroyo watershed, an urbanized watershed with concrete-lined arroyo channels in the northeastern quadrant of Albuquerque that exhibits flashy, monsoonal-driven storm runoff. Model results were compared to observed discharge data, according to literature-recommended performance measures and performance evaluation criteria. The HEC-HMS model using the Soil Conservation Service (SCS) curve number $(\mathrm{CN})$ and SCS unit hydrograph methods ranked the highest when averaging the individual performance measures (Nash-Sutcliffe Efficiency, percent bias, and coefficient of determination) rankings together across the hourly calibration and validation periods, followed by P8, which was tied with the HEC-HMS initial and constant approach. For daily rankings using the same rank-averaging approach, the HEC-HMS CN-based model and P8 were tied for the highest ranking, followed by the HEC-HMS initial and constant approach. Alternatively, rating performance using validation period results as an

\footnotetext{
1U.S. Geological Survey.
}

${ }^{2}$ U.S. Department of Agriculture. indication of the expected confidence in forecasted results for future conditions, the P8 model performed best for both hourly and daily time-steps, followed by the HEC-HMS CN-based model and the HEC-HMS initial and constant-based model. However, based on the literature performance evaluation criteria, the HEC-HMS and P8 models overall had marginally satisfactory performance only for operation at the daily time-step. Direct comparison of the HEC-HMS and P8 models to the AHYMO is difficult, given the different performance assessment criteria used to assess these models separately in this study, as recommended by the literature. The AHYMO results generally lacked precision, given the wide range in the performance assessment values across events in percent error in peak discharge, difference in timing of peak discharge, percent error in total runoff volume, and difference in duration of event relative to observed data. For some events, however, the AHYMO results were fairly accurate, and AHYMO was likely a good predictor of the timing of storm runoff and the shape of the hydrograph. This study did not assess the results for all potential applications of the models in the Albuquerque urbanized area. Further study may be required to assess the model performance capabilities in other modeling applications.

\section{Introduction}

Compliance with a current U.S. Environmental Protection Agency (EPA) watershed-based National Pollutant Discharge Elimination System (NPDES) permit issued for the local government entity City of Albuquerque (COA), New Mexico, requires understanding of rainfall-runoff hydrology in small urban watersheds. The purpose of this NPDES permit is to help control point sources of water pollution in surface waters of the United States. According to NPDES standards, municipal separate storm sewer systems (MS4s) in the Albuquerque urbanized area (fig. 1) are point sources that discharge stormwater into large water bodies, and are subject to regulation (EPA, 2019).

Improved understanding of rainfall-runoff hydrology for small watersheds will improve the ability of the COA to make informed management decisions and will help meet 
the requirements of its NPDES permit. Although monitoring of stormwater quantity and quality from small watersheds is not an explicit requirement of the City's NPDES permit, understanding rainfall and the subsequent runoff (rainfallrunoff) characteristics at the small, urban watershed scale will improve understanding of rainfall-runoff hydrology for urban watersheds that drain into the Rio Grande. Discharge in most small watersheds in the Albuquerque metropolitan area has not been monitored previously, and it is not practical for the City to measure discharge on the extensive network of storm-drainage channels that collect surface water from small watersheds in the area for two reasons: (1) NPDES permit cycles typically last for less than 5 years (EPA, 2019), and (2) NPDES permit requirements can change between cycles. Thus, there is no guarantee, especially in the small watersheds, that the infrastructure required to perform continuous stormwater monitoring will be needed in the next permit cycle. For these reasons, quantifying stormflow in the area may be best accomplished by using computer-based rainfall-runoff models.

Several hydrologic modeling software packages have been developed and are available, and each has distinct strengths and limitations. Factors to consider when choosing a hydrologic simulation model include whether the conceptual hydrologic model is suitable for the area of interest, the type and resolution of model outputs needed to meet study objectives, the availability of usable model calibration data, and the accuracy of the output. In general, more complex models require more data for parameterization and more user expertise to obtain useful results, though more complex models are not necessarily more accurate for all rainfall-runoff scenarios. Most importantly for the current study, one of the goals for the $\mathrm{COA}$ was to select a rainfall-runoff model that finds a balance between accuracy and ease of use.

Previous studies in the application of rainfall-runoff models to the urbanized area of Albuquerque have either used observed data to assess the performance of a single model, or directly compared the output of two separate models in the absence of observed data (Knutilla and Veenhuis, 1994; Schoener, 2010). In the study described in this report, the U.S. Geological Survey (USGS), in cooperation with the COA, compared the output of three separate models to observed data and evaluated the performance of the models in relation to each other. The specific objectives of the study were to (1) select and set up three models to simulate storm runoff in a small urbanized watershed in Albuquerque; (2) assess the capabilities of the models to estimate hourly and daily storm runoff; and (3) assess the "trade-offs" of the models in terms of their accuracy and usability, or ease of use, for future application in the Albuquerque metropolitan area. Additionally, results of this study could help inform model users who have interest in simulating storm runoff in similar urban areas throughout the United States. Model input and output data can be accessed in the associated data release by Shephard and Douglas-Mankin (2020).

\section{Purpose and Scope}

This purpose of this report is to describe the comparison of three rainfall-runoff models - the Hydrologic Engineering Center Hydrologic Modeling System (HEC-HMS); the Program for Predicting Polluting Particle Passage Through Pits, Puddles, and Ponds (P8); and the Arid-Lands Hydrologic Model (AHYMO) - with respect to their ability to simulate storm runoff in the Hahn Arroyo watershed, which exhibits conditions representative of the area and has adequate data to support model development, application, and testing. The models were compared on the basis of their performance in simulating discharge using available monitoring data; no new data were collected for the purpose of this study. The results of the study are intended to help the COA determine the utility of the HEC-HMS and P8 models relative to the currently used AHYMO for simulating stormwater flows in Albuquerque. Additionally, results of this study could help inform model users who have interest in simulating storm runoff in similar urban areas throughout the United States.

\section{Description of Study Area}

The city of Albuquerque (hereinafter, Albuquerque) is in north-central New Mexico. Most of the city east of the Rio Grande is built on the alluvial fans of the Sandia Mountains (Storms and others, 2015), where elevations range from about 5,000 to 7,000 feet (ft) (Veenhuis, 2003). The city land area is approximately 188 square miles, and the population in 2018 was estimated to be approximately 560,218 people (U.S. Census Bureau, 2018). Urbanization increased rapidly in the past several decades, with most of the development occurring in the northeast quadrant of the city since the 1980 s and on the west side of the Rio Grande since the 1990s (Veenhuis, 2003). An estimated 243,402 housing units were in Albuquerque as of 2017 (U.S. Census Bureau, 2017).

The spatial domain for the study described in this report was the Hahn Arroyo watershed, defined by the drainage area upstream from the Hahn Arroyo streamgage (USGS 08329840, Hahn Arroyo in Albuquerque, N.M.), in the northeast quadrant of Albuquerque (fig. 1). The Hahn Arroyo watershed was selected for the study largely due to the duration and quality of available discharge and precipitation data within or near the basin. Hahn Arroyo was also considered a well-suited watershed for this study because it is intermediate in size relative to other urban watersheds within the Albuquerque area, contains the drainage infrastructure commonly found elsewhere in Albuquerque, and has a mix of commercial, residential, and other land-use conditions representative of much of the Albuquerque urban area.

An analysis of elevation data from the COA (2018a) indicates that the average slope in the Hahn Arroyo watershed is approximately 5 percent, with a minimum slope of 0 percent, and a maximum slope of 20 percent. The average elevation is 
approximately $5,422 \mathrm{ft}$, with a minimum elevation of $5,177 \mathrm{ft}$ and a maximum elevation of 5,984 ft. Approximately 64 percent of the underlying soils in the watershed are classified as Hydrologic Soil Group (HSG) A, and 36 percent are classified as HSG B, based on Web Soil Survey Data (Soil Survey Staff, Natural Resources Conservation Service, U.S. Department of Agriculture, 2018). The HSG A soils are classified as EmB (Embudo gravelly fine sandy loam, 0 to 5 percent slopes) and EtC (Embudo-Tijeras complex, 0 to 9 percent slopes), and the HSG B soils are classified as $\mathrm{TgB}$ (Tijeras gravelly fine sandy loam, 1 to 5 percent slopes). Land use in the watershed is approximately 64 percent residential, 10 percent commercial/industrial/office, 22 percent roads, and 4 percent other miscellaneous usage, based on land-use data from the COA (COA, 2018a). The average parcel size of the residential lots is approximately 0.26 acre (COA, 2018a).

The stormwater conveyance system within Albuquerque consists of natural and concrete-lined arroyo channels, as well as underground storm sewers that direct storm runoff through the city and into the Rio Grande (Albuquerque Metropolitan Arroyo Flood Control Authority [AMAFCA], 2019). The channels typically have measurable discharge only during and immediately following rainstorms or periods of rapid snowmelt. Some channels have built-in flood-control structures, such as detention ponds and dams, though many of the channels in the urban part of the city remain free-flowing and unobstructed. Surface-drain inlets for the storm sewers exist extensively throughout the city, and storm sewers typically direct water into the drainage channels. Drainage infrastructure is owned and maintained by several agencies, including AMAFCA, Bernalillo County, COA, and New Mexico Department of Transportation. The Hahn Arroyo is a concrete-lined channel that flows from east to west, with north and south forks that join near its outlet point where discharge is measured (fig. 1).

Albuquerque has a semiarid climate, with an average annual precipitation of about 8 inches (in.) in the lower elevations of the city and about $12 \mathrm{in}$. at the higher elevations (National Oceanic and Atmospheric Administration [NOAA], 2019). Between 2008 and 2018, 64 percent of the annual precipitation total occurred between July and October at the National Weather Service Albuquerque International Sunport Weather Station (NOAA, 2019). Precipitation that falls between July and October is typically associated with the North American Monsoon, consisting of localized convective cell monsoonal rainstorms often of high rainfall intensity, which may lead to high runoff during storm events (Veenhuis, 2003). 


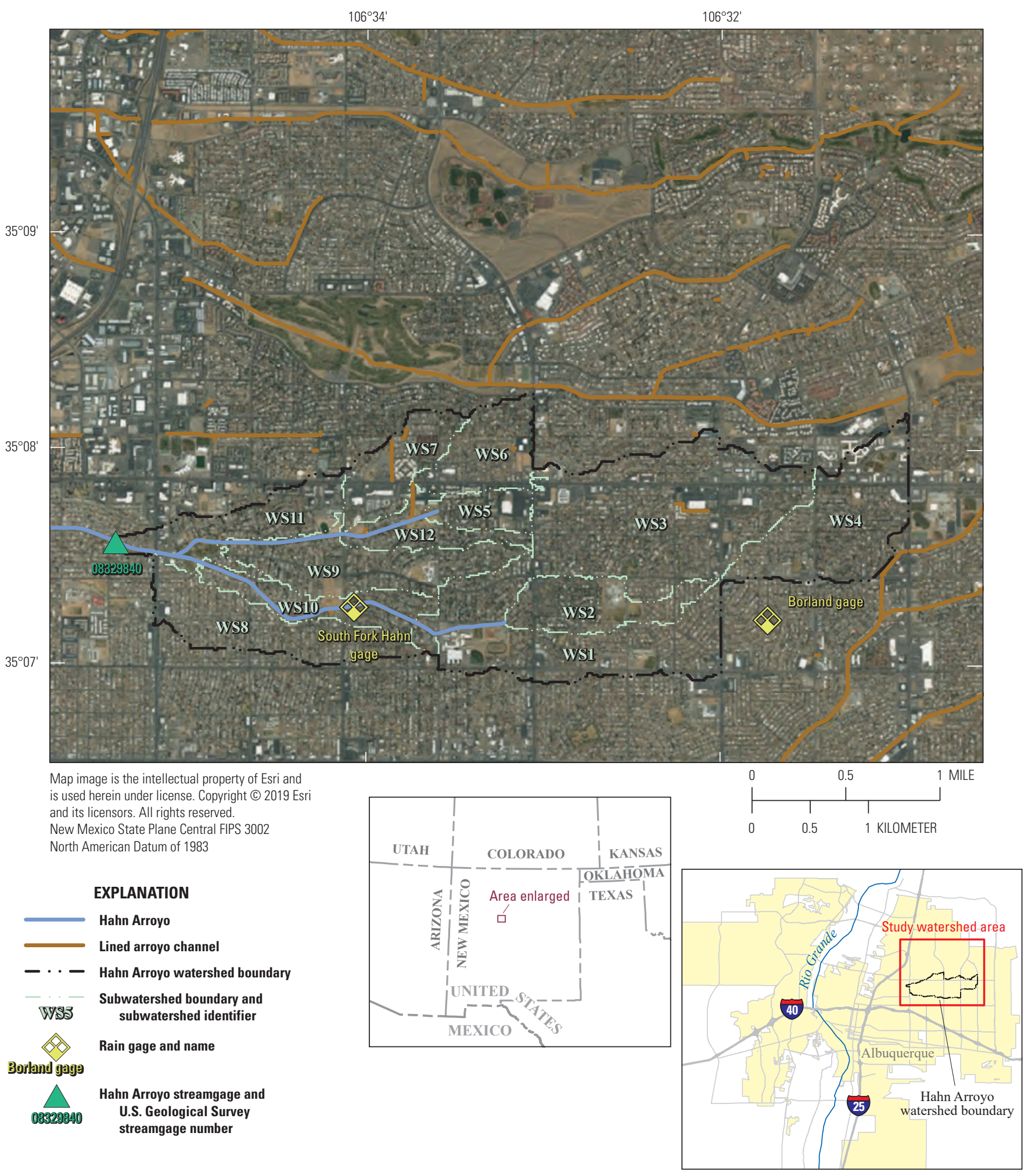

Figure 1. Location of the study watershed, the Hahn Arroyo watershed in Albuquerque, New Mexico. The numbers directly on the map (WS1, for example) indicate the delineated subwatersheds as they relate to model configuration. Map displays the Hahn Arroyo streamgage (USGS 08329840, Hahn Arroyo in Albuquerque, N.M.), the South Fork Hahn gage (USGS 08329838, SF Hahn Arroyo in Albuquerque, N.M.), and the Borland rain gage (USGS 350713106314230, Borland Rain Gage in Albuquerque, N.M.). 


\section{Watershed Model Descriptions}

Three watershed model software packages were selected for assessment in this study, with four distinct model setups that will be discussed later in this report. Basic characteristics of each model are discussed in the following sections, and briefly summarized in table 1 .

\section{Hydrologic Engineering Center Hydrologic Modeling System (HEC-HMS)}

The HEC-HMS was developed by the U.S. Army Corps of Engineers (USACE) to simulate rainfall-runoff and routing processes. The system includes modules that simulate evapotranspiration, infiltration, runoff, base flow, and open-channel routing (USACE, 2000) and is now widely used and accepted by the hydrologic modeling community. HEC-HMS is built on more than 30 years of experience with hydrologic simulation software and includes modernized algorithms from HEC software dating back to 1989. HEC-HMS is intended to simulate precipitation-runoff processes in dendritic watershed systems across a wide range in size of geographic areas, from large river basins to small urban or natural watersheds (USACE, 2016). HEC-HMS version 4.2.1, released in March 2017, was used for modeling in this study (USACE, 2017a).

HEC-HMS computes discharge at the subwatershed scale and allows users to define homogeneous response units. Runoff simulation requires (at a minimum) input of precipitation data and subwatershed characteristics. Advanced modules within HEC-HMS also require input data such as temperature, solar radiation, or canopy cover. Model outputs include tabular hydrograph information and additional options for graphical display. The program also generates summary results and statistics for model simulations and can display results in different units. HEC-HMS has built-in capabilities to estimate parameters automatically. Parameters are estimated through optimization trials based on goodness-of-fit between the computed and observed discharge for different parameter values and different user-specified objective functions. HEC-HMS also gives users the ability to assess model uncertainty by using the Monte Carlo method.

Of the three models used in this report, HEC-HMS provides users with the largest assortment of simulation methods and equations. HEC-HMS version 4.2.1 allows users to select from 12 different precipitation loss methods. Most of the methods are used for event modeling, while some methods allow for simple continuous modeling. All of the methods use a mass conservation approach. HEC-HMS provides a total of eight different precipitation-excess transform methods, including unit hydrograph methods and linear quasi-distributed methods. Additionally, there are various methods to simulate base-flow contributions to outflow, as well as methods to simulate flow in open channels. Water impoundments and diversion structures can be represented as well.
In this study, HEC-HMS models were developed by using two different approaches. The two approaches used different precipitation loss methods and shared the same transform method. The first approach used the Soil Conservation Service (SCS) curve number (CN) method, and the second approach was the initial and constant infiltration method. The SCS unit hydrograph was used as a precipitation-excess transform method for either approach. Therefore, two separate model setups were used, and the performance of each was assessed separately. To clarify, one setup used the SCS-CN loss method and SCS unit hydrograph transform method, while the other setup used the initial and constant infiltration loss method and the SCS unit hydrograph transform method. The first setup used the same loss and transform methods recommended in local expertise documented guidance (AMAFCA, 2018).

\section{Program for Predicting Polluting Particle Passage Through Pits, Puddles, and Ponds (P8)}

The P8 Urban Catchment Model (Walker, 1990, 1997; IEP, Inc., 1990; Walker and Walker, 2017) is a spatially distributed model that uses a water- and mass-balance approach to simulate generation and transport of stormwater and associated contaminants through an urban watershed. The primary intended use of P8 is to make "relative" water-quality predictions, expressed in terms of percent removals of contaminants, but the model also simulates discharge. P8 was originally developed in 1990 for the Microsoft Disk Operating System (MS-DOS) and was converted to the Windows operating system in 2006. The P8 model is freely available online, and technical assistance is available for a fee (Walker and Walker, 2017). P8 version 3.5 , released in 2015 , was used in this study (Walker and Walker, 2017).

P8 can simulate hourly stormflow discharge and has capabilities of simulating transport of sediment (total suspended solids), total phosphorus, total Kjeldahl nitrogen, lead, copper, zinc, and total hydrocarbons. The simulated area is a user-defined network of watershed areas (up to 192) interconnected by water treatment devices for conveyance and treatment (up to 48). P8 operates on an hourly time step, which might preclude use in small watersheds with high-intensity, short-duration (subhourly) storms. Watershed areas generate both pervious-area runoff, using the SCS-CN method, and impervious-area runoff, assumed to equal the rainfall rate in excess of depression storage. Watershed area outflows are directly routed to treatment devices, with no lag, for storage, treatment, and discharge, though a time of concentration (Tc) parameter can be specified to attenuate the runoff volume. Water treatment devices include buffers/swales, pipes/manholes, splitters, detention ponds, infiltration basins, aquifers, and user-defined storage/discharge structures. Runoff and mass flux of constituents are tracked and balanced into and out of each device. Flow from watershed areas is routed sequentially through treatment devices in downstream order, with device outflows calculated according to stage-volume-discharge relations for infiltration, controlled outflow, and spillway outflow, as appropriate, from each device. 
Table 1. Characteristics and input requirements for the HEC-HMS, P8, and AHYMO models, specific to their usage in this study.

[HEC-HMS, Hydrologic Engineering Center Hydrologic Modeling System; P8, Program for Predicting Polluting Particle Passage Through Pits, Puddles, and Ponds; AHYMO, Arid-Lands Hydrologic Model; SCS-CN, Soil Conservation Service curve number; SCS, Soil Conservation Service; CN, curve number; min, minute; DEM, digital elevation model; Tc, time of concentration]

\begin{tabular}{|c|c|c|c|c|c|c|c|c|}
\hline \multirow[b]{2}{*}{ Model program } & \multicolumn{2}{|c|}{ Equations } & \multicolumn{2}{|c|}{ Resolution } & \multicolumn{2}{|c|}{ Raw input data } & \multirow[b]{2}{*}{ Model output } & \multirow{2}{*}{$\begin{array}{c}\text { User interface/ease } \\
\text { of use }\end{array}$} \\
\hline & Loss method(s) & $\begin{array}{l}\text { Transform } \\
\operatorname{method}(s)\end{array}$ & Spatial & Temporal & Nongeospatial & Geospatial & & \\
\hline HEC-HMS & $\begin{array}{l}\text { SCS-CN, initial and } \\
\text { constant method }\end{array}$ & $\begin{array}{l}\text { SCS-unit hydro- } \\
\text { graph }\end{array}$ & subwatershed & $5 \mathrm{~min}$ & $\begin{array}{l}\text { Precipitation, } \\
\text { CNs, land } \\
\text { use (initial } \\
\text { abstraction, } \\
\text { constant loss } \\
\text { rate) }\end{array}$ & $\begin{array}{l}\text { Arroyos, storm pipes, } \\
\text { storm pipe inlets, } \\
\text { soils, land use, } \\
\text { DEM, Thiessen } \\
\text { polygons/gage } \\
\text { weights }\end{array}$ & $\begin{array}{l}\text { Raw discharge } \\
\text { time-series data, } \\
\text { discharge charts, } \\
\text { discharge graph, } \\
\text { summary statistics }\end{array}$ & $\begin{array}{l}\text { Highly user friendly } \\
\text { (all graphical), } \\
\text { built in calibra- } \\
\text { tion functionality. }\end{array}$ \\
\hline P8 & SCS-CN & $\begin{array}{l}\text { None (direct } \\
\text { runoff), but Tc } \\
\text { can be speci- } \\
\text { fied }\end{array}$ & subwatershed & 1 hour & $\begin{array}{l}\text { Precipitation, } \\
\text { CNs }\end{array}$ & $\begin{array}{l}\text { Arroyos, storm pipes, } \\
\text { storm pipe inlets, } \\
\text { soils, land use, } \\
\text { DEM, Thiessen } \\
\text { polygons/gage } \\
\text { weights }\end{array}$ & $\begin{array}{l}\text { Raw discharge time- } \\
\text { series data, sum- } \\
\text { mary statistics }\end{array}$ & $\begin{array}{l}\text { Moderately user } \\
\text { friendly (mix } \\
\text { of text files and } \\
\text { graphical). }\end{array}$ \\
\hline AHYMO & $\begin{array}{l}\text { Initial abstraction/ } \\
\text { uniform infiltra- } \\
\text { tion with split } \\
\text { hydrographs }\end{array}$ & $\begin{array}{l}\text { SCS Upland } \\
\text { Method }\end{array}$ & subwatershed & $5 \mathrm{~min}$ & $\begin{array}{l}\text { Precipitation, } \\
\text { land treat- } \\
\text { ment (initial } \\
\text { abstraction, } \\
\text { infiltration } \\
\text { loss rate) }\end{array}$ & $\begin{array}{l}\text { Arroyos, storm pipes, } \\
\text { storm pipe inlets, } \\
\text { land use, DEM, } \\
\text { Thiessen poly- } \\
\text { gons/gage weights }\end{array}$ & $\begin{array}{l}\text { Raw discharge time- } \\
\text { series data, lag time/ } \\
\text { time to peak calcu- } \\
\text { lations, summary } \\
\text { statistics }\end{array}$ & $\begin{array}{l}\text { No graphical inter- } \\
\text { face (all text files } \\
\text { and command } \\
\text { line). }\end{array}$ \\
\hline
\end{tabular}




\section{Arid-Lands Hydrologic Model (AHYMO)}

The AHYMO was developed from the U.S. Department of Agriculture (USDA), Agricultural Research Service (ARS) Hydrologic Model (HYMO; Williams and Hann, 1973) in an effort by AMAFCA to better represent hydrologic conditions in New Mexico. AHYMO was extensively revised and enhanced by C.E. Anderson and is now maintained by the COA (COA, 2018b). The intended use of the program is for the design of flood-control structures or for land-use regulation in flood plains. AHYMO generates a hydrograph time series given a specific rainfall distribution and subwatershed properties. The most recent version, AHYMO-S4-R2 (COA, 2018 b), was used in this study. The model was verified for conditions of the greater Albuquerque area and has been considered a useful tool by local engineers and hydrologists (Schoener, 2010).

AHYMO users can subdivide the model domain into homogenous subwatersheds, and the model can store up to 600 input data points to simulate rainfall-runoff events at a wide range of temporal scales. AHYMO uses cumulative rainfall input and subwatershed characteristics to drive rainfallrunoff processes. The model stores a hydrograph with up to 4,000 points (typically a 0.01 -hour increment is used for 6 - or 24-hour storm events). Input data are created and stored in an American Standard Code for Information Interchange (ASCII) text file, and the output data are stored in a 132-column ASCII text file, which can be viewed in a text editor. In addition, the program provides a summary table file, which can be viewed and printed. Guidance for setting up model simulations has been developed by local hydrology and engineering professionals and is documented in the Hydrology section (Ch. 22, Section 2) of the Albuquerque Development Process Manual (DPM) (COA, 2019).

The AHYMO model can compute hydrographs by using various methods, including a unit hydrograph approach (ARS HYMO unit hydrograph) and SCS-CN for soil infiltration. To calculate runoff volume in AHYMO, the Albuquerque DPM recommends the "split-hydrograph" approach, which uses the combined subwatershed initial abstraction/uniform infiltration, which in turn applies separate infiltration values and unit hydrographs for pervious and impervious areas of each subwatershed. This "split-hydrograph" approach is documented by Anderson and Heggen (1991). Land-use classifications called "land treatment types" are used as input for the calculations. The infiltration factors for the land treatments have been determined specifically for use in New Mexico and are described in tables A-4, A-5, A-6, and A-7 in Ch. 22, Section 2 of the DPM (COA, 2019). Areal watershed percentages of land treatment types are dependent on land use and land parcel size and can be populated in the model by following the guidance of table D-3 in Section 2 of the Southern Sandoval County Arroyo Flood Control Authority (SSCAFCA) DPM (SSCAFCA, 2009). For runoff transform, the Tc, lag time, and time to peak (Tp) are parameters used by AHYMO to determine peak storm runoff rates and hydrograph shape. Based on the DPM guidance, AHYMO uses three different equations to compute the Tc for larger watersheds. The SCS Upland Method is used for reach lengths shorter than 4,000 ft, the U.S. Department of Interior Bureau of Reclamation lag-time equation (COA, $2018 \mathrm{~b}$ ) is used for reach lengths longer than $12,000 \mathrm{ft}$, and a transition equation is used for reach lengths between 4,000 and $12,000 \mathrm{ft}$. Tp is assumed to be a constant ratio of the Tc, calculated as $\mathrm{Tp}=2 / 3 \mathrm{Tc}(\mathrm{COA}, 2019)$.

These three models were chosen for specific reasons, dependent upon their suitability for the modeling needs of the COA. HEC-HMS was chosen because of its wide use, making it easily accessible and increasing the chance that future model users will be familiar with it. Additionally, HEC-HMS was chosen for its variability when it comes to its equation selection, making it suitable for a wide range of hydrologic processes. Although P8 was chosen primarily for its urbanspecific capabilities, the built-in water-quality modeling function made it more desirable. The application of a model with discharge and water-quality simulation capabilities may be desirable in that it has the potential to address multiple issues that are relevant to model users in the Albuquerque area. Finally, AHYMO was chosen because it was developed specifically for use in the Albuquerque area and has been used by local professionals since its creation. An advantage that all three models share is that they are free and easily accessible, which increases the likelihood that they will be used for local projects that have budget limitations.

\section{Study Methods}

The following sections describe the process of delineating the watershed boundary for the models and discuss the input data requirements and format. Additionally, the following sections describe the methods for calibrating the models and criteria used in assessing the quality of the model performance.

\section{Watershed Delineation}

Urban watershed delineation was conducted in ArcMap version 10.6.1 (Esri, 2018) following a methodology similar to that of Parece and Campbell (2015). The general workflow was to determine the topographic-based watershed boundary and then modify the boundary to account for urban stormwater infrastructure such as storm pipes, artificial channels, and road gutters that may divert water across natural topographic watershed divides. Raw data for the watershed delineation included a 2-ft contour topographic shapefile, publicly available online through the COA (COA, 2018a), that was converted to a digital elevation model (DEM) with a cell size of $50 \mathrm{ft}$ by $50 \mathrm{ft}$ by using the Topo to Raster Tool in ArcMap, version 10.6.1 (Esri, 2018). The Fill tool was applied to the DEM to fill any sinks and repair DEM imperfections. After the DEM was prepared, a standard workflow for delineating watersheds in ArcMap 
(Esri, 2018) was applied. This workflow entailed creating a flow direction raster with the Flow Direction tool and using the new flow direction raster to create a flow accumulation raster with the Flow Accumulation tool. The accumulated flow path of the flow accumulation raster was spatially in agreement with the lower part of the Hahn Arroyo concrete channel, which was overlain as a line shapefile. A point shapefile of the USGS streamgage Hahn Arroyo in Albuquerque, NM (USGS 08329840) was used as the watershed pour point, which was "snapped" to the flow accumulation raster by using the Snap Pour Point tool and then used as the pour point in the Watershed tool. The Watershed tool created a DEM, or topography-based, watershed of the Hahn Arroyo.

Storm sewers and artificial channels divert water in and out of the topography-based watershed. A shapefile was acquired from the COA that contained all the inlets to the storm sewers in Albuquerque. These inlets were used as new pour points to create small watersheds for each of the inlets. The connectedness of the inlets and infrastructure either to the Hahn Arroyo or to other nearby arroyos determined whether the area draining into the inlets were added or subtracted from the original topographic watershed. Final adjustments were made manually on the basis of an interpretation of how roads intersected and rerouted stormflow, and from field reconnaissance ground-truthing.

\section{Model Input and Data Selection}

Each model had slightly different requirements for the type and format of the data they used. The following sections describe the data used in the calibration and model assessment process, as well as the input data used to run the models.

\section{Discharge Data}

The discharge data used for model calibration and validation were collected at the Hahn Arroyo streamgage (USGS 08329840 Hahn Arroyo in Albuquerque, N.M.) (USGS, 2019). Discharge was reported in cubic feet per second at 5-minute intervals. Data gaps existed, but typically were short lived and were during dry, or no-flow, periods. The 5-minute interval discharge data were used in calibrating and validating HEC-HMS. The hourly maximums of the observed 5-minute data were used as calibration data for P8, which simulates discharge at a 1-hour time-step interval. Statistical model performance evaluation between the observed and simulated discharge data for HEC-HMS and P8 were calculated with hourly maximum and daily maximum values, and unadjusted 5-minute data were used with AHYMO.

\section{Precipitation Data}

Data from two rain gages in or near the Hahn Arroyo were used for model inputs. The USGS Borland rain gage (USGS 350713106314230, Borland Rain Gage in
Albuquerque, N.M.) recorded 5-minute interval precipitation data between October 1, 2007, and January 6, 2016. The South Fork Hahn gage (USGS 08329838, SF Hahn Arroyo in Albuquerque, N.M.) recorded 5-minute interval precipitation data as early as October 1, 2007, and was still recording data during the preparation of this report (2019). The South Fork Hahn gage also has historically recorded discharge, though these data were not used in this report. Five-minute precipitation data were downloaded from the USGS National Water Information System (NWIS) Web Interface (USGS, 2019). For some periods, the collection interval for the rain gages was 6 minutes, and though there are many periods of missing data, these gaps were short lived and were typically during periods of no precipitation and no flow in the arroyo channels. In most cases, the 5- or 6-minute incremental precipitation data were input directly into the HEC-HMS program. For use as model input with $\mathrm{P} 8$, precipitation data were formatted in hourly time steps by summing the 5 - or 6-minute incremental rainfall over the course of an hour. Five-minute incremental data were also formatted as cumulative event rainfall for use in AHYMO.

\section{Soils, Land-Use, Elevation, and Other Watershed Data}

Soils data were downloaded from the Natural Resources Conservation Service (NRCS) Web Soil Survey site (Soil Survey Staff, Natural Resources Conservation Service, U.S. Department of Agriculture, 2018). Land-use, zoning, parcel, and elevation data are publicly available online with their associated documentation and metadata from the $\mathrm{COA}(\mathrm{COA}$, 2018a). Elevation data were converted from the original format of 2 -ft contours to a raster dataset with a resolution of 50by 50 -ft raster cells. The original elevation data were created in 2010 by the COA.

\section{Watershed Model Calibration}

With the exception of AHYMO, the models were calibrated in order to ensure the best performance possible. The following sections describe the model calibration methods.

\section{Calibration Strategy}

The simulated discharge outputs of HEC-HMS and P8 were calibrated to observed discharge data at the Hahn Arroyo streamgage. The calibration period for these two models spanned nearly 2 years (October 4, 2011, to October 1, 2013, for HEC-HMS, and October 4, 2011, to September 24, 2013, for P8) and included approximately 20 observed events. AHYMO calibration was not necessary in this study because AHYMO parameters previously determined for this study area (documented in the DPM; COA, 2019) were available.

Calibration of HEC-HMS for both model setups was conducted with the built-in parameter optimization module within the HEC-HMS software program. In this study, 
calibration in HEC-HMS was performed on a 5-minute time interval, with the Nash-Sutcliffe coefficient as the objective function. The objective function was minimized by using the univariate gradient method, which successively adjusts each parameter while holding the others constant to achieve the best goodness-of-fit between the observed and simulated data.

Calibration and uncertainty analysis for P8 was conducted by using the model-independent Parameter Estimation and Uncertainty Analysis (PEST) program (Doherty, 2018a, b). PEST is a commonly used program for automatic environmental model calibration and uncertainty analysis. It implements traditional parameter estimation approaches on the basis of a few parameters by running a model as many times as needed while adjusting parameters to reach a best fit between the simulated and observed data by minimizing weighted least squares errors. PEST also supports highly parameterized, regularized inversion by using hundreds to thousands of parameters. In addition, PEST allows users to characterize the parameter and predictive uncertainty. PEST is built to communicate with a model through the model's own input and output files.

Input files for PEST were created with the assistance of the time-series processor (TSPROC). TSPROC is a general-purpose tool for processing time-series datasets but was designed with the intent to assist in the model calibration process by preparing time-series data and required input files for PEST (Westenbroek and others, 2012). P8 runs with a graphical user interface (GUI), and PEST is designed to run models by gaining access to their input and output files. Additional scripts were created to pair the use of P8 with PEST. A batch file was created to run in PEST and act as a model pre- and postprocessor. This batch file consists of a series of simple scripts that launch and run the P8 model and reformat the model output data in order to be passed along as input for PEST. In this series of scripts, first the P8 model is launched from the Windows command line. Then, a script is executed with the freely available keyboard macro program AutoHotKey that automatically navigates the P8 GUI and runs the model. Finally, a PowerShell script reformats the P8 output data into a format that can be read by PEST, and the P8 program is closed by another AutoHotKey script.

\section{Calibration Parameters}

Parameters that directly altered the total runoff volume, timing and magnitude of peak flow, and the event duration were specifically chosen for calibration. Sensitivity analysis was conducted on the chosen parameters to verify their influence on the output. The parameters chosen for calibration in the HEC-HMS CN-based model were the CNs for each subwatershed, the $\mathrm{CN}$ initial abstraction (Ia) value for each subwatershed, and the lag time for the SCS unit hydrograph for each watershed. The parameters chosen for calibration in the HEC-HMS initial and constant-based model were the initial loss, the constant loss rate, and the lag time for the SCS unit hydrograph. The parameters chosen for calibration in P8 were the $\mathrm{CNs}$, Tc, and rainfall breakpoint (cumulative rainfall threshold for when all precipitation is converted to runoff).

CNs can be altered to represent antecedent moisture conditions prior to an event. Parameter ranges for $\mathrm{CNs}$ were determined by converting $\mathrm{CN}_{\mathrm{II}}$, for an average antecedent moisture condition $(\mathrm{AMC})$, to dry antecedent conditions $\left(\mathrm{CN}_{\mathrm{I}}\right)$ with the Sobhani formula (Sobhani, 1975) and to wet antecedent conditions $\left(\mathrm{CN}_{\mathrm{III}}\right)$ with the Hawkins formula (Hawkins and others, 1985), as suggested by Mishra and others (2008), giving a reasonable range of $\mathrm{CNs}$ for a wide range of moisture conditions. Initial $\mathrm{CN}_{\mathrm{II}}$ values for HEC-HMS and P8 were determined for the HSG and cover descriptions for each subwatershed area by using charts from USDA TR-55, table 2-2a (NRCS, 1986). Preliminary runs of the model yielded results that overestimated the storm runoff magnitude and volume, so parameter ranges were constrained to encompass only dry to average $\mathrm{AMC}\left(\mathrm{CN}_{\mathrm{I}}\right.$ to $\left.\mathrm{CN}_{\mathrm{II}}\right)$ for calibration. Ia values were set to be a representative range of the wet-season $\mathrm{CN}$ values, using the relation between Ia and the $\mathrm{CN}$ value (combining eqs. 2-2 and 2-4 from NRCS, 1986):

$$
I a=0.2 \frac{1,000-10 * C N}{C N}
$$

Initial lag-time values for the $\mathrm{CN}$ and initial and constantbased models in HEC-HMS and P8 were determined by using the lag-time values calculated in AHYMO because lag times were calculated with cited methods in AHYMO (COA, 2018b). Lag-time ranges were set so as not to constrain parameter adjustments during calibration. Initial loss rates and constant loss rates using the initial and constant-based HECHMS models were also determined from the AHYMO-derived parameter values, which were chosen to fit within the "land treatment" A-D values in the DPM (COA, 2019). Tc values in P8 were limited by the time step of 1 hour, which is large compared to the lag times used in the other models, so the parameter range was set between 0 and 1 hour by using the P8 default of 0 hours for the initial values. The default rainfall breakpoint value in P8 was used, which was originally determined with Source Area Loading and Management Model calibrations (Walker and Walker, 2017), and the same parameter range values were used as the $\mathrm{CN}$ Ia as previously described.

\section{Model Performance Assessment and Model Validation}

Model performance was evaluated by using recommended guidance from Harmel and others $(2014,2018)$ and Moriasi and others (2015), which assesses model performance based on quantitative performance measures and graphical methods. The quantitative performance measures for both HEC-HMS model setups and the P8 model were the NashSutcliffe model efficiency coefficient (NSE), coefficient of determination $\left(\mathrm{R}^{2}\right)$, and percent bias (PBIAS). Moriasi and others (2015) provide recommended ranges of these 
Comparison of Storm Runoff Models for a Small Watershed in an Urban Metropolitan Area, Albuquerque, N.M.

performance measure values in relation to their level of satisfactory performance, ranging from "not satisfactory" to "very good." These quantitative performance evaluation criteria are recommended for the daily, monthly, and annual timescales. In this study, the temporal scales used to assess model performance are daily and hourly, meaning the standards being applied to the hourly scale are likely stricter than necessary, but may be more applicable given the nature of monsoon storms and urban storm runoff. Moriasi and others (2015) recommend separate event-based performance measures for models that cannot be run continuously. AHYMO can store only 600 data input points, so recommended performance measures for AHYMO include the difference in Tp and peak flow discharge magnitude, difference in duration of event, and difference in event flow volume. Graphical methods for all models include hydrograph comparisons. Model performance measures were run on hourly and daily time steps, where the maximum hourly and maximum daily values were compared between the simulated and observed discharge data.

Model validation involved assessing model performance by using the "best-fit" calibrated parameters applied to a separate time period. The validation-data period was 3.5 months (June 15, 2014, to October 1, 2014) and included approximately 15 events. The shorter validation period relative to the calibration period was a result of the lack of continuous periods of available input or output data that had ideal rainfall events and minimal data gaps. It was decided that the calibration period should be longer than the validation period to ensure the best possible performance from the models. The assessment of model performance was focused on the monsoon season, when most of storm runoff occurs in Albuquerque, which is when the validation period was targeted.

The validation period had lower magnitude rainfallrunoff events than did the calibration period. The calibration period had a wide range of flow event magnitudes, ranging from less than 100 cubic feet per second $\left(\mathrm{ft}^{3} / \mathrm{s}\right)$ to a maximum of $776 \mathrm{ft} 3 / \mathrm{s}$, with the maximum flow events occurring during the monsoon season. During the validation period, observed stormflow never exceeded $200 \mathrm{ft} 3 / \mathrm{s}$ and remained in the lower end of the range from the calibration period. The validation period was shorter (3.5 months) than the calibration period ( 2 years) and only covered the monsoon season. During the calibration period, maximum precipitation intensity was 4.92 inches per hour (in/h) (for the duration of one 5-minute interval) at the Borland rain gage and $3.6 \mathrm{in} / \mathrm{h}$ (for the duration of one 5-minute interval) at the South Fork Hahn gage. During the validation period, precipitation intensity reached 2.88 in $/ \mathrm{h}$ (for the duration of one 5-minute interval) at the Borland gage and $3.6 \mathrm{in} / \mathrm{h}$ (for the duration of one 5 -minute interval) at the South Fork Hahn gage. The cumulative precipitation at the Borland gage was 2.50 in. for the 2012 monsoon season, $9.05 \mathrm{in}$. for the 2013 monsoon season, and 4.08 in. during 2014. At the South Fork Hahn gage, the 2012 and 2013 cumulative monsoon season precipitation amounts were 2.25 and
9.92 in., respectively, and the 2014 the cumulative monsoon precipitation was $4.5 \mathrm{in}$. Although there was a wider range of precipitation conditions during the calibration period than during the validation period, the cumulative precipitation in the validation period remained within the range of that in the calibration period.

\section{Model Data Requirement Comparison}

The three models assessed in this study have different data requirements. Those requirements are described here and summarized in table 1.

\section{Input Data Comparison}

The HEC-HMS and AHYMO model programs accept subwatershed-specific precipitation input, and weighting schemes can be applied at the subwatershed level, rather than at the watershed level. HEC-HMS requires incremental precipitation data, and 5-minute incremental data were typically used in this study. AHYMO requires cumulative precipitation input for each subwatershed, so users must convert incremental precipitation data to cumulative precipitation and develop station-weighted precipitation values for each subwatershed. Precipitation-station weights must be user-defined for each subwatershed in HEC-HMS, but the weighting calculation is done by the model rather than by the user. AHYMO uses observed cumulative rainfall data at a temporal resolution defined by the user. AHYMO also provides 17 different rainfall distributions of hypothetical storms, depending on the intended use and specified location of the model. AHYMO can use up to 4,000 points to store an output hydrograph, accepts up to 600 points as input data, and provides users with complete control on the time increment used as a decimal hour value (COA, 2018b). Observed cumulative precipitation with a time increment of 5 minutes, or 0.08333 hour, was used in this study, though one stormflow event used time increments of 6 minutes, or 0.1 hour, given that it was the only available data.

Precipitation input data for P8 are in hourly intervals and are incremental rather than cumulative. The input precipitation file is an ASCII text file, and P8 has a built-in function that converts an Excel .xls file to the correct ASCII text file format used for model input. Precipitation data from the USGS are typically collected at 5-minute temporal intervals, and conversion of the precipitation data from 5-minute to hourly time intervals requires an extra intermediate step before the data can be used with P8. The P8 model allows for only one precipitation input file for the entire model domain, meaning that each model subwatershed is assumed to have the same rainfall distribution. In this report, station-weighted precipitation calculated with the Thiessen Polygon method for the entire watershed is used as input data (Thiessen, 1911). 
Temperature data were not used in any of the model inputs for this study although HEC-HMS and P8 allow for temperature inputs. Temperature input data for P8 are daily average air temperature. Air-temperature data are used to drive the simulation of evapotranspiration from components within the P8 model called "aquifer devices" as well as from snowfall and snowmelt. Air-temperature data are not required, however, if the model does not utilize aquifer devices, or if the flow event is not dependent on precipitation in the form of snowfall. Evapotranspiration is commonly omitted from event storm models and considered negligible for the short duration of the events, and temperature input data were not used for the HEC-HMS models in this study. Temperature data can be used, however, for loss methods that use a detailed accounting of evapotranspiration, such as the soil moisture accounting method. AHYMO does not accept temperature as an input.

For all three models, a DEM and drainage infrastructure geospatial data are required to delineate the urban watershed; however, the geospatial data requirements vary slightly among the three models. Soils data are required to derive $\mathrm{CNs}$ for HEC-HMS and P8 but are not necessarily required for deriving parameters in AHYMO. In AHYMO, land treatment types that determine the Ia and loss rates are derived from zoning or land-use geospatial data, along with parcel lot data, because the size of lot and land-use type together determine the percentages of each land treatment type within the parcel. In P8, zoning or land-use data are required for determining the indirectly connected impervious-area fraction. Land-parcel data (lot polygons) are used together with the zoning data to determine the directly connected impervious-area fraction.

Average watershed slope, derived from the DEM, is necessary for determining the depression storage value in P8. Reach slope is used in AHYMO for runoff transform methods. Although it was not used in this study, the HEC-GeoHMS program is available as an extension toolkit that is designed for model users with limited geographic information system (GIS) experience to develop hydrologic modeling inputs for HEC-HMS (USACE, 2017b). AHYMO and P8 do not have GIS utility programs, so the spatially derived inputs for these models are determined manually by using a GIS.

\section{User Interface and Model Setup}

User interaction varies among the three models. In HEC-HMS, all input data can be manually entered into the GUI. This differs from the P8 model, which does use a GUI to organize the input data for model runs, but the data are prepared in text files. HEC-HMS gives the user the ability to use text files through a U.S. Army Corps of Engineers' Hydrologic Engineering Center Data Storage System (HEC-DSS) format file as the primary input source, but this is not a requirement. Though the preferred usability of the GUIs may be subjective to the user, some users may find the P8 GUI to be less intuitive than the HEC-HMS GUI. The P8 GUI does not display a spatial representation of the model and relies heavily on dropdown menus rather than panel displays. Input data and model parameters are specified in ASCII files for AHYMO, and the model is executed through a command line. In P8, input data are imported in spreadsheets; however, the model parameters and model simulation initiation are carried out through a GUI.

The AHYMO interface is command-line based and accepts text input files. One main input file contains all the input data used in the model simulation, and ancillary files tell the model which files to store the output data in. AHYMO is unique in that it runs from the content of a single input file. This provides an advantage from a data management and organization perspective; however, users must create separate input files for each event, which contain the precipitation input data as well as the subwatershed information and parameters. In contrast, other models will save the subwatershed data, and users simply supply new precipitation input data. The AHYMO text input file can be time consuming to set up, because precipitation data must be manually pasted and properly indented in the text file to comply with the margin formatting.

HEC-HMS gives users three broad options for entering rainfall data. Precipitation data can be from an observed rainfall event, from a frequency-based event, or from the upper limit of possible precipitation for a given area, with the latter two options considered as hypothetical or design storms. HEC-HMS has built-in capabilities to aid in the simulation of these hypothetical and design storms. Each precipitation input type can serve its own purpose. In this study, however, observed rainfall data from historical events were used to carry out the calibration and model performance assessment. HEC-HMS can prepare weighted precipitation values for each subwatershed when a user specifies the gage weights. Because of this capability, the user supplies only the gage data and weights and does not calculate the weighted precipitation values, whereas these calculations must be made by the user in either P8 or AHYMO. HEC-HMS gives users a wide range of potential temporal resolutions for precipitation input data, with the finest resolution of 1-minute intervals and the coarsest resolution of 1-day intervals. Five-minute resolution input data were used in this study to coincide with the resolution of the observed rainfall data. In contrast to P8 and AHYMO, HEC-HMS automates modeling process more than the other two models, making model preparation more efficient. For example, data can be input directly into the user interface, rather than by creating text files, and precipitation weighting is calculated by the program. HEC-HMS also has the advantage of built-in optimization and has graphical and statistical performance evaluation capabilities. 


\section{Model Process Assessment and Model Limitations}

The three models assessed here take different approaches to calculating discharge, and each model has limitations in providing the best balance of accuracy and usability in simulating storm runoff. In this study, HEC-HMS utilized the SCS-CN and the initial and constant methods for calculating total runoff volume in response to precipitation input. These methods share similarities with the methods used in both P8 and AHYMO. P8 uses the SCS-CN method on pervious surfaces; on impervious surfaces, it applies a $\mathrm{CN}$ value of 98 until cumulative precipitation exceeds a user-specified breakpoint, after which all precipitation runs off (direct runoff coefficient of 1.0). HEC-HMS is similar in that it uses the SCS-CN method on pervious surfaces, though it assumes all precipitation runs off impervious surfaces. Users can specify the Ia value in the CN approach in HEC-HMS but not in P8. The Ia/constant infiltration method used in AHYMO is similar to the initial and constant loss model used in HEC-HMS. Both models assume a constant precipitation loss rate following an initial loss of precipitation that represents interception and depression storage. The Ia and constant infiltration in AHYMO are determined by the model based on the areal percentages of land treatment types in each subwatershed, but HEC-HMS recommends determining the parameter values through the calibration process.

The three models transform runoff volume differently. The SCS unit hydrograph method is used to transform the runoff volume in both HEC-HMS models. This method is a parametric unit hydrograph model that relates the Tp to a userspecified lag time; HEC-HMS indicates that the lag can be estimated through calibration in gaged watersheds. P8 directly routes the excess runoff volume to the outlet device of each subwatershed, with the assumption that the subwatershed Tc is small relative to the precipitation time step of 1 hour. The P8 documentation acknowledges that this may cause watershed response time for larger subwatersheds to be underestimated. In AHYMO, the Tp is assumed to be a constant ratio of the Tc, which is determined computationally based on the length of the subwatershed reach.

All three models assume a spatially homogenous subwatershed but use different temporal resolutions. HEC-HMS and AHYMO can operate at subhourly temporal resolutions, whereas P8 is limited to 1-hour intervals. Given the flashy (high intensity, short duration) behavior of the precipitation events and response hydrographs in the Albuquerque area, the 1-hour intervals used in P8 may not be appropriate for simulating the timing of peak stormflow event discharge or the shape of the hydrograph. AHYMO and HEC-HMS operate at a temporal resolution more suitable for the stormflow events that occur in Albuquerque. In addition to the coarse temporal resolution of the P8 model, there is concern with the issue of its spatial distribution of precipitation data. P8 does not allow for subwatershed-scale distribution of precipitation and applies only one precipitation time series to the entire study area. This input precipitation data can be a single gage-weighted dataset derived from multiple gages, but in an area such as Albuquerque, where precipitation has high spatial heterogeneity, this approach may not capture the differences in volume and timing of precipitation in subwatersheds.

A limitation of the loss methods used in all three models is that they do not explicitly account for changes in the antecedent moisture conditions during the model simulation period. For HEC-HMS and P8, the models are run for extended periods of time that span several storm runoff events, but with a parameter set that does not adjust to the changing antecedent conditions. The parameters are calibrated to best fit the range of events during the calibration period but may be more or less suited to a varying range of antecedent conditions and specific storm runoff events. Additionally, the simplicity of the various loss methods does not necessarily allow for direct interpretation in terms of hydrologic processes because the loss methods lump various characteristics (soil type, land use, antecedent moisture, among others) into single parameters. Given the event-based storm runoff, the application of these models would be to run the events individually and alter the parameters accordingly on the basis of antecedent conditions, which will not be the same for all events.

\section{Model Performance Assessment}

The three models were compared and evaluated on the basis of their quantitative and visual performance characteristics. Model parameter values and sensitivities are summarized in tables 2, 3, and 4, and performance measures and performance evaluation criteria are summarized in tables 5, 6, 7, 8, and 9, which include model rankings relative to one another. Model output can be accessed in the Shephard and DouglasMankin (2020) data release. 
Table 2. Initial parameter values and ranges, as well as the optimized parameter values and parameter sensitivities for the HEC-HMS curve-number-based model calibration process.

[HEC-HMS, Hydrologic Engineering Center Hydrologic Modeling System; WS, subwatershed; SCS, Soil Conservation Service; in., inch; min, minute; - , unitless]

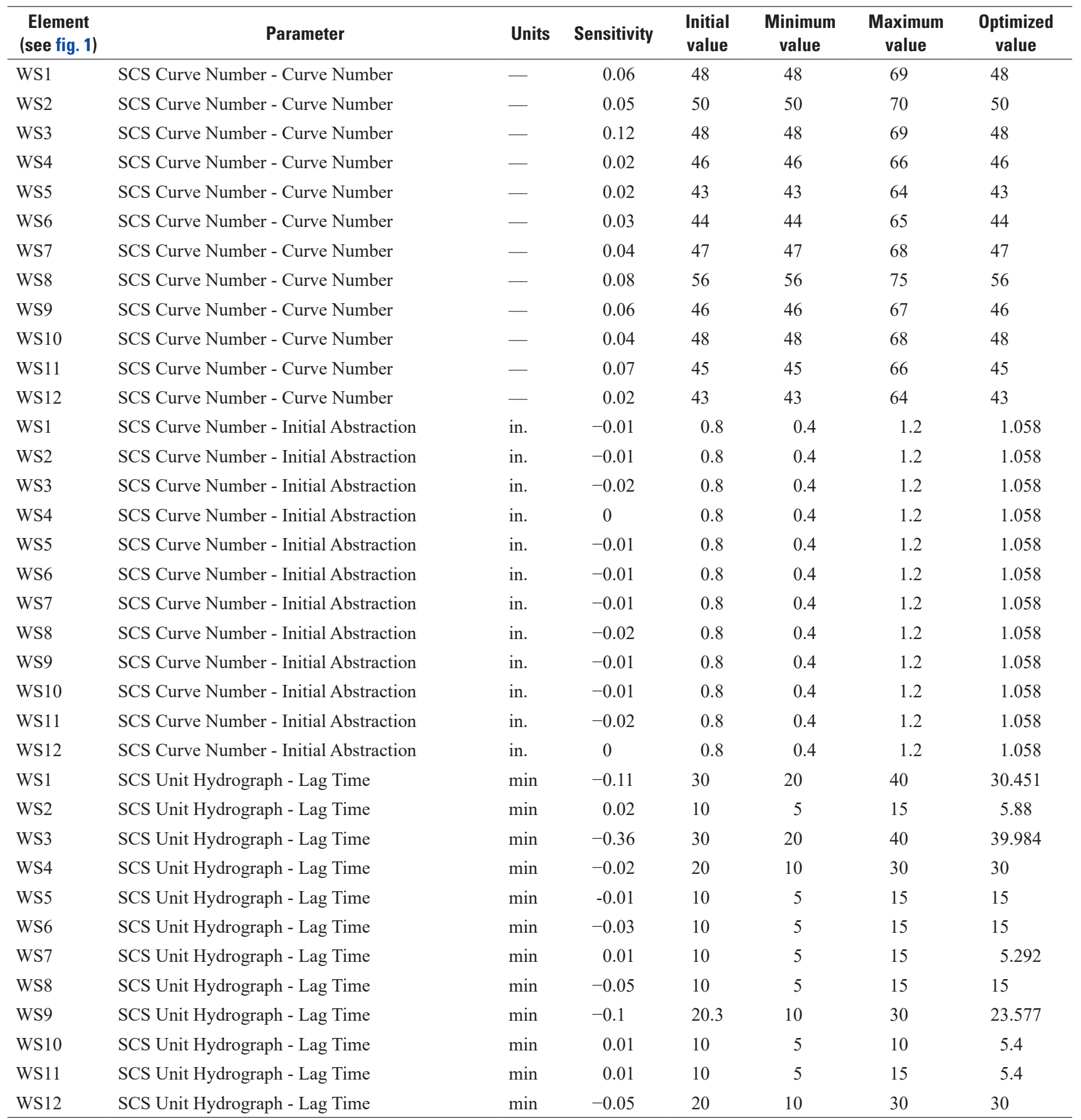


Table 3. Initial parameter values and ranges, as well as the optimized parameter values and parameter sensitivities for the HEC-HMS initial and constant infiltration-based model calibration process.

[HEC-HMS, Hydrologic Engineering Center Hydrologic Modeling System; WS, subwatershed; in/h, inch per hour; min, minute]

\begin{tabular}{|c|c|c|c|c|c|c|c|}
\hline $\begin{array}{c}\text { Element } \\
\text { (see fig. 1) }\end{array}$ & Parameter & Units & Sensitivity & Initial value & $\begin{array}{c}\text { Minimum } \\
\text { value }\end{array}$ & $\begin{array}{l}\text { Maximum } \\
\text { value }\end{array}$ & $\begin{array}{l}\text { Optimized } \\
\text { value }\end{array}$ \\
\hline WS1 & Initial and Constant - Initial Loss & in. & 0 & 0.43977 & 0.3 & 0.6 & 0.43977 \\
\hline WS2 & Initial and Constant - Initial Loss & in. & 0 & 0.4457 & 0.3 & 0.6 & 0.4457 \\
\hline WS3 & Initial and Constant - Initial Loss & in. & 0 & 0.426 & 0.3 & 0.6 & 0.426 \\
\hline WS4 & Initial and Constant - Initial Loss & in. & 0 & 0.43471 & 0.3 & 0.6 & 0.43471 \\
\hline WS5 & Initial and Constant - Initial Loss & in. & 0 & 0.43015 & 0.3 & 0.6 & 0.43015 \\
\hline WS6 & Initial and Constant - Initial Loss & in. & 0 & 0.43056 & 0.3 & 0.6 & 0.43056 \\
\hline WS7 & Initial and Constant - Initial Loss & in. & 0 & 0.43099 & 0.3 & 0.6 & 0.43099 \\
\hline WS8 & Initial and Constant - Initial Loss & in. & 0 & 0.42846 & 0.3 & 0.6 & 0.42846 \\
\hline WS9 & Initial and Constant - Initial Loss & in. & 0 & 0.42951 & 0.3 & 0.6 & 0.42951 \\
\hline WS10 & Initial and Constant - Initial Loss & in. & 0 & 0.4184 & 0.3 & 0.6 & 0.4184 \\
\hline WS11 & Initial and Constant - Initial Loss & in. & 0 & 0.43381 & 0.3 & 0.6 & 0.43381 \\
\hline WS12 & Initial and Constant - Initial Loss & in. & 0 & 0.42565 & 0.3 & 0.6 & 0.42565 \\
\hline WS1 & Initial and Constant - Constant Rate & $\mathrm{in} / \mathrm{hr}$ & -0.02 & 1.08136 & 1 & 1.2 & 1.0976 \\
\hline WS2 & Initial and Constant - Constant Rate & $\mathrm{in} / \mathrm{hr}$ & 0.01 & 1.09797 & 1 & 1.2 & 1.0591 \\
\hline WS3 & Initial and Constant - Constant Rate & $\mathrm{in} / \mathrm{hr}$ & -0.04 & 1.0428 & 1 & 1.2 & 1.0584 \\
\hline WS4 & Initial and Constant - Constant Rate & $\mathrm{in} / \mathrm{hr}$ & 0 & 1.06719 & 1 & 1.2 & 1.0833 \\
\hline WS5 & Initial and Constant - Constant Rate & $\mathrm{in} / \mathrm{hr}$ & 0 & 1.05443 & 1 & 1.2 & 1.0703 \\
\hline WS6 & Initial and Constant - Constant Rate & $\mathrm{in} / \mathrm{hr}$ & -0.01 & 1.05556 & 1 & 1.2 & 1.0715 \\
\hline WS7 & Initial and Constant - Constant Rate & in $/ \mathrm{hr}$ & -0.01 & 1.05678 & 1 & 1.2 & 1.0727 \\
\hline WS8 & Initial and Constant - Constant Rate & $\mathrm{in} / \mathrm{hr}$ & -0.01 & 1.04968 & 1 & 1.2 & 1.0655 \\
\hline WS9 & Initial and Constant - Constant Rate & $\mathrm{in} / \mathrm{hr}$ & -0.01 & 1.05262 & 1 & 1.2 & 1.0685 \\
\hline WS10 & Initial and Constant - Constant Rate & $\mathrm{in} / \mathrm{hr}$ & -0.01 & 1.02153 & 1 & 1.2 & 1.0369 \\
\hline WS11 & Initial and Constant - Constant Rate & $\mathrm{in} / \mathrm{hr}$ & -0.01 & 1.06466 & 1 & 1.2 & 1.0807 \\
\hline WS12 & Initial and Constant - Constant Rate & $\mathrm{in} / \mathrm{hr}$ & 0 & 1.04181 & 1 & 1.2 & 1.0575 \\
\hline WS1 & SCS Unit Hydrograph - Lag Time & $\min$ & -0.01 & 30 & 20 & 40 & 34.845 \\
\hline WS2 & SCS Unit Hydrograph - Lag Time & $\min$ & 0.02 & 10 & 5 & 15 & 6.4027 \\
\hline WS3 & SCS Unit Hydrograph - Lag Time & $\min$ & -0.02 & 30 & 20 & 40 & 34.844 \\
\hline WS4 & SCS Unit Hydrograph - Lag Time & $\min$ & -0.02 & 20 & 10 & 30 & 30 \\
\hline WS5 & SCS Unit Hydrograph - Lag Time & $\min$ & -0.02 & 10 & 5 & 15 & 15 \\
\hline WS6 & SCS Unit Hydrograph - Lag Time & $\min$ & -0.05 & 10 & 5 & 15 & 15 \\
\hline WS7 & SCS Unit Hydrograph - Lag Time & $\min$ & -0.05 & 10 & 5 & 15 & 15 \\
\hline WS8 & SCS Unit Hydrograph - Lag Time & $\min$ & 0 & 10 & 5 & 15 & 10.143 \\
\hline WS9 & SCS Unit Hydrograph - Lag Time & $\min$ & -0.13 & 20 & 10 & 30 & 20.3 \\
\hline WS10 & SCS Unit Hydrograph - Lag Time & $\min$ & 0 & 10 & 5 & 10 & 10 \\
\hline WS11 & SCS Unit Hydrograph - Lag Time & $\min$ & -0.04 & 10 & 5 & 15 & 15 \\
\hline WS12 & SCS Unit Hydrograph - Lag Time & $\min$ & -0.08 & 20 & 10 & 30 & 30 \\
\hline
\end{tabular}


Table 4. Initial parameter values and ranges, as well as the optimized parameter values and parameter sensitivities for the P8 model calibration process.

[P8, Program for Predicting Polluting Particle Passage Through Pits, Puddles, and Ponds; rb, rainfall breakpoint; tc, time of concentration; cn, curve number; in., inch; hr, hour; - , unitless]

\begin{tabular}{|c|c|c|c|c|c|c|}
\hline Parameter & Units & Sensitivity & Initial value & Minimum value & Maximum value & Optimized value \\
\hline $\mathrm{rb} 1$ & in. & 0.00633 & 0.8 & 0.4 & 1.2 & 1.2 \\
\hline tc 1 & $\mathrm{hr}$ & 0.00154 & 0 & 0 & 1 & 1.0 \\
\hline tc2 & $\mathrm{hr}$ & 0.00240 & 0 & 0 & 1 & 0.000 \\
\hline tc3 & $\mathrm{hr}$ & 0.01169 & 0 & 0 & 1 & 0.000 \\
\hline tc 4 & $\mathrm{hr}$ & 0.02848 & 0 & 0 & 1 & 0.000 \\
\hline tc5 & $\mathrm{hr}$ & 0.03199 & 0 & 0 & 1 & 0.000 \\
\hline tc6 & $\mathrm{hr}$ & 0.00406 & 0 & 0 & 1 & 1.000 \\
\hline tc7 & $\mathrm{hr}$ & 0.00135 & 0 & 0 & 1 & 0.000 \\
\hline tc 8 & $\mathrm{hr}$ & 0.00255 & 0 & 0 & 1 & 0.0 \\
\hline tc9 & $\mathrm{hr}$ & 0.00599 & 0 & 0 & 1 & 1.0 \\
\hline tc10 & $\mathrm{hr}$ & 0.00949 & 0 & 0 & 1 & 1.0 \\
\hline tc 11 & $\mathrm{hr}$ & 0.04388 & 0 & 0 & 1 & 0.7 \\
\hline $\mathrm{cn} 1$ & - & 0.00001 & 69 & 48 & 69 & 48 \\
\hline $\mathrm{cn} 2$ & - & 0.00002 & 70 & 50 & 70 & 50 \\
\hline $\mathrm{cn} 3$ & - & 0.00003 & 69 & 48 & 69 & 48 \\
\hline cn4 & - & 0.00000 & 66 & 46 & 66 & 46 \\
\hline $\operatorname{cn} 5$ & - & 0.00035 & 64 & 43 & 64 & 47 \\
\hline cn6 & - & 0.00006 & 65 & 44 & 65 & 44 \\
\hline cn7 & - & 0.00000 & 68 & 47 & 68 & 47 \\
\hline cn8 & - & 0.00002 & 75 & 56 & 75 & 56 \\
\hline $\operatorname{cn} 9$ & - & 0.00006 & 67 & 46 & 67 & 46 \\
\hline $\operatorname{cn} 10$ & - & 0.00001 & 68 & 48 & 68 & 48 \\
\hline cn11 & - & 0.00148 & 66 & 45 & 66 & 66 \\
\hline cn12 & - & 0.00025 & 64 & 43 & 64 & 51.944 \\
\hline
\end{tabular}

\section{Hydrologic Engineering Center Hydrologic Modeling System (HEC-HMS)}

Two separate model setups were used in HEC-HMS. The following sections describe the performace quality of each setup separately.

\section{Curve Number Approach}

During the calibration process, the HEC-HMS optimization algorithms found that the $\mathrm{CN}$ parameters had positive sensitivity, ranging from 0.02 to 0.12 (table 2), with the largest sensitivity being the $\mathrm{CN}$ parameter for subwatershed 3 (fig. 1), one of the largest subwatersheds in the study area. The Ia parameters for each subwatershed were found to be less sensitive than the $\mathrm{CN}$ parameters and consistently negative or zero, ranging from -0.02 to 0 . The sensitivity responses of the lag-time parameters were positive and negative and were of larger magnitude relative to the sensitivities of other parameter groups, with the larger watersheds having larger sensitivities, up to -0.36 . Using NSE as the objective function during calibration likely led to the lag-time parameters having a higher sensitivity than the $\mathrm{CN}$ or Ia parameters; lag time affects alignment of observed and simulated hydrographs, with important consequences on NSE. Using a metric such as the peak discharge magnitude or storm runoff volume would likely increase the influence of the $\mathrm{CN}$ and Ia, which control the peak storm runoff rate and storm runoff volume. Regardless, the optimized parameters of the $\mathrm{CN}$ were selected at the bottom of the parameter range for all parameters, and the Ia values were at the highest end of the parameter range. Therefore, using another objective function (NSE, peak discharge, or total runoff volume) likely would have yielded similar results. 
Table 5. Calibration period model performance measures, performance evaluation criteria, and relative model rank for HEC-HMS and P8 models.

[NSE, Nash-Sutcliffe model efficiency coefficient; PBIAS, percent bias; R², coefficient of determination; PR, performance rating; HEC-HMS, Hydrologic Engineering Center Hydrologic Modeling System; P8, Program for Predicting Polluting Particle Passage Through Pits, Puddles, and Ponds; ns, not satisfactory; s, satisfactory; g, good]

\begin{tabular}{|c|c|c|c|c|c|c|c|c|c|c|c|c|c|c|c|c|c|c|}
\hline \multicolumn{19}{|c|}{ Calibration } \\
\hline \multirow{2}{*}{ Model } & \multicolumn{6}{|c|}{ NSE } & \multicolumn{6}{|c|}{ PBIAS } & \multicolumn{6}{|c|}{$\mathbf{R}^{2}$} \\
\hline & Hourly & PR & Rank & Daily & PR & Rank & Hourly & PR & Rank & Daily & PR & Rank & Hourly & PR & Rank & Daily & PR & Rank \\
\hline $\begin{array}{l}\text { HEC-HMS curve } \\
\text { number }\end{array}$ & 0.23 & ns & 2 & 0.47 & ns & 2 & 16.2 & ns & 1 & 6.2 & g & 1 & 0.51 & ns & 1 & 0.57 & ns & 2 \\
\hline $\begin{array}{l}\text { HEC-HMS initial } \\
\text { and constant }\end{array}$ & 0.46 & ns & 1 & 0.54 & $\mathrm{~s}$ & 1 & -33.8 & ns & 3 & -27.7 & ns & 3 & 0.47 & ns & 2 & 0.54 & ns & 3 \\
\hline P8 & -0.80 & ns & 3 & 0.42 & ns & 3 & 33.1 & ns & 2 & 9.2 & g & 2 & 0.16 & ns & 3 & 0.58 & ns & 1 \\
\hline
\end{tabular}

Table 6. Validation period model performance measures, performance evaluation criteria, and relative model rank for HEC-HMS and P8 models.

[NSE, Nash-Sutcliffe model efficiency coefficient; PBIAS, percent bias; R², coefficient of determination; PR, performance rating; HEC-HMS, Hydrologic Engineering Center Hydrologic Modeling System; P8, Program for Predicting Polluting Particle Passage Through Pits, Puddles, and Ponds; ns, not satisfactory; s, satisfactory; g, good]

\begin{tabular}{|c|c|c|c|c|c|c|c|c|c|c|c|c|c|c|c|c|c|c|}
\hline \multicolumn{19}{|c|}{ Validation } \\
\hline \multirow{2}{*}{ Model } & \multicolumn{6}{|c|}{ NSE } & \multicolumn{6}{|c|}{ PBIAS } & \multicolumn{6}{|c|}{$\mathbf{R}^{2}$} \\
\hline & Hourly & PR & Rank & Daily & PR & Rank & Hourly & PR & Rank & Daily & PR & Rank & Hourly & PR & Rank & Daily & PR & Rank \\
\hline $\begin{array}{l}\text { HEC-HMS curve } \\
\text { number }\end{array}$ & -6.39 & ns & 2 & -6.97 & ns & 2 & 153.5 & ns & 3 & 207 & ns & 3 & 0.52 & ns & 1 & 0.77 & $\mathrm{~g}$ & 1 \\
\hline $\begin{array}{l}\text { HEC-HMS initial } \\
\text { and constant }\end{array}$ & -8.27 & ns & 3 & -10.40 & ns & 3 & 139.5 & ns & 2 & 204 & ns & 2 & 0.44 & ns & 2 & 0.69 & $\mathrm{~s}$ & 2 \\
\hline P8 & -0.58 & ns & 1 & 0.35 & ns & 1 & -12 & $\mathrm{~s}$ & 1 & -14 & $\mathrm{~s}$ & 1 & 0.06 & ns & 3 & 0.44 & ns & 3 \\
\hline
\end{tabular}


Table 7. Summarized model performance measures rankings for HEC-HMS and P8 models. Averaged separately for NSE, PBIAS, and $\mathrm{R}^{2}$ across the calibration and validation periods, giving rankings for overall performance with consideration of both the calibration and validation period.

[NSE, Nash-Sutcliffe model efficiency coefficient; PBIAS, percent bias; R², coefficient of determination; HEC-HMS, Hydrologic Engineering Center Hydrologic Modeling System; P8, Program for Predicting Polluting Particle Passage Through Pits, Puddles, and Ponds; tied, tied for the same ranking]

\begin{tabular}{l|cc|cc|cc}
\hline & \multicolumn{2}{|c|}{ Calibration period rankings } & Validation period rankings & \multicolumn{2}{c}{ Combined period rankings } \\
\hline & Hourly time step & Daily time step & Hourly time step & Daily time step & $\begin{array}{c}\text { Hourly time } \\
\text { step }\end{array}$ & $\begin{array}{c}\text { Daily time } \\
\text { step }\end{array}$ \\
\hline HEC-HMS curve number & 1 & 1 & 2 & 2 & 1 & 1 (tied) \\
HEC-HMS initial and constant & 2 & 3 & 3 & 3 & 2 (tied) & 3 \\
P8 & 3 & 2 & 1 & 1 & 2 (tied) & 1 (tied) \\
\hline
\end{tabular}

During the calibration period, visual inspection of the observed and simulated discharge time-series graphs indicated a general agreement between the simulated $\mathrm{CN}$-based model and the observed data, in terms of the timing and occurrence of stormflow events (fig. $2 A$ ). The $\mathrm{R}^{2}$ values for the calibration period showed a positive correlation $\left(\mathrm{R}^{2}=0.51\right.$ hourly, 0.57 daily), which fell just outside the range considered to be satisfactory (satisfactory $\mathrm{R}^{2} \geq 0.60$; Moriasi and others, 2015) (table 5). Although observed and simulated discharge were generally (at least visually) in agreement during the monsoon season, observed discharge events were often absent during the winter months where simulated discharge events are present (fig. 2). As indicated by the PBIAS values (PBIAS = 16.2 percent hourly, 6.2 percent daily), the model does tend to overpredict the magnitude and volume of stormflow but still produced results that were good at the daily scale and almost satisfactory at the hourly scale (satisfactory PBIAS < \pm 15 percent; Moriasi and others, 2015). The NSE value for the hourly $(\mathrm{NSE}=0.23)$ and daily $(\mathrm{NSE}=0.47)$ time steps were positive, indicating that the model was a better predictor than the observed average; however, the NSE values were still considered not satisfactory at the hourly scale and marginally not satisfactory at the daily scale by literature standards (satisfactory NSE $\geq 0.50$; Moriasi and others, 2015). Ultimately, the performance of HEC-HMS when using the CN-based approach during the calibration period was marginally satisfactory at the daily scale but generally not satisfactory at the hourly scale. Among the two HEC-HMS model setups and the P8 model, the HEC-HMS model with CN-based approach ranked the highest on average among the three performance statistics for both the hourly and daily time steps, but ranked second in hourly and daily NSE and second in daily R2 .

The CN-based HEC-HMS model generally performed more poorly during the validation period than during the calibration period for both hourly and daily time steps (table 6). The model overpredicted discharge by a larger magnitude $($ PBIAS $=153.5$ percent hourly, 207 percent daily) than during the calibration period, and the NSE values were highly negative (NSE $=-6.39$ hourly, -6.97 daily). However, the daily R 2 value improved during the validation period, rating as good performance $\left(\mathrm{R}^{2}=0.77\right)$, and the hourly $\mathrm{R}^{2}$ value remained similar $\left(\mathrm{R}^{2}=0.52\right)$, with an improvement of 0.01 over the hourly $\mathrm{R}^{2}$ value during the calibration period $\left(\mathrm{R}^{2}=0.51\right)$. Ultimately, during the validation period, this model ranked second on average on both the hourly and daily performace statistics. The model ranked second in hourly and daily NSE, third in PBIAS, and first in $\mathrm{R}^{2}$. Reasons for the not satisfactory rating during validation may include the short validation period and the differences in the precipitation and storm runoff regime mentioned in the "Model Performance Assessment and Model Validation" section of this report.

\section{Initial and Constant Approach}

During the calibration process, the HEC-HMS optimization algorithms found, similarly to the $\mathrm{CN}$-based setup, that the initial and constant-based setup lag-time parameters had higher sensitivity than the parameters that influence total runoff volume, such as the initial or constant loss parameters. The initial loss parameters were not found to be sensitive by HECHMS (sensitivity $=0$ ), so their initial values were not changed during calibration (table 3 ). The constant loss rate parameters were found to have relatively low sensitivity $(-0.04$ to 0.01$)$ and were found to not be sensitive (sensitivity $=0$ ) in three of the subwatersheds. The lag-time parameter sensitivities were both positive and negative and had a larger magnitude sensitivity relative to the other parameter groups. Lag-time parameters in the larger subwatersheds had the largest sensitivity, ranging as much as -0.13 . Again, it is possible that using the NSE as the objective function caused the initial and constant loss rate parameters to be less sensitive. The model used the initial parameters for the initial loss rate and did not use the largest constant loss rate values.

The initial and constant-based approach in HEC-HMS outperformed the other two models (without including AHYMO) during the calibration period when looking only at hourly and daily NSE, but ranked second hourly and third daily (fig. $3 \mathrm{~A}$; table 5) on average when looking at all three performance statistics. There were similarities in the visual agreement in terms of timing and occurrence of stormflow events to the other models, including a better visual agreement during the monsoon season than during the winter months 
(fig. $3 A$ ). The initial and constant approach $\mathrm{R}^{2}$ value was not satisfactory at the hourly timescale (0.47) or at the daily timescale (0.54), although the daily value was relatively close to the satisfactory threshold of 0.60 (table 5). The model performance as assessed by PBIAS was considered not satisfactory (satisfactory PBIAS $< \pm 15$ percent; Moriasi and others, 2015), with values that suggest underprediction by the model at the hourly timescale (PBIAS $=-33.8$ percent) and at the daily timescale (PBIAS $=-27.7$ percent). NSE was marginally unsatisfactory at the hourly scale $(\mathrm{NSE}=0.46)$ but was satisfactory at the daily scale $(\mathrm{NSE}=0.54)$. Overall, performance of the HEC-HMS initial and constant-based approach was not satisfactory at the hourly timescale and not satisfactory to satisfactory at the daily timescale.

This initial and constant infiltration-based HEC-HMS model quantitatively performed more poorly during the validation period than during the calibration period in terms of the NSE (NSE $=-8.27$ hourly, -10.40 daily) and PBIAS (PBIAS $=139.5$ percent hourly, 204 percent daily) performance statistics (table 6). During the validation period, the $\mathrm{R}^{2}$ values were satisfactory and higher than during the calibration period at the daily timescale and similar to the values during the calibration period at the hourly timescale (calibration $\mathrm{R}^{2}=0.47$ hourly, 0.54 daily; validation $\mathrm{R}^{2}=0.44$ hourly, 0.69 daily) (table 6 ). The initial and constant infiltration-based HEC-HMS model ranked third on average on hourly and daily performance statistics during the validation period. The model ranked third in hourly and daily NSE, second in hourly and daily PBIAS, and second in hourly and daily $\mathrm{R}^{2}$ for the validation period. Reasons for the poor performance during validation may include the short validation period and the differences in the precipitation and storm runoff regime mentioned in the "Model Performance Assessment and Model Validation" section of this report.

\section{Program for Predicting Polluting Particle Passage Through Pits, Puddles, and Ponds (P8)}

Calibration with PEST determined that generally the most sensitive P8 parameters were the Tc parameters, with sensitivities ranging from 0.00135 to 0.04388 among the 11 water treatment devices for the 12 subwatersheds (table 4). Six of the 11 Tc-optimized parameter values remained at the initial value of 0 . The rainfall breakpoint parameter had a sensitivity of 0.00633 . The P8 user's manual states that flow may be overrepresented in larger watersheds and increasing Tc can attenuate flows. Given the large hourly time step for P8, however, attenuating the flows may decrease the quantitative performance of the model. The sensitivity of $\mathrm{CN}$ values was small (average $=0.00019$ ), and most of the initial values, which are at the lower end of the parameter value range, were retained after the calibration process. Ultimately, almost two-thirds of the P8 parameters remained at initial values following the calibration process. The result that model calibration in this study was achieved with minimal change from initial parameter values may be considered beneficial, because it may indicate that initial default or pre-determined parameters values are sufficient for reasonable model results.

Similar to the other two models, there was general agreement in the P8 simulation results between observed and simulated discharge (fig. 4). At the daily scale, calibrated model performance was good for PBIAS (9.2 percent) and marginally not satisfactory for $\mathrm{R}^{2}(0.58)$ and NSE (0.42) (table 5). At the hourly scale, calibrated model performance was not satisfactory for all statistics $\left(\mathrm{R}^{2}=0.16\right.$; PBIAS $=33.1$; $\left.\mathrm{NSE}=-0.80\right)$. The positive PBIAS values indicate that the model typically overpredicted discharge at the hourly and daily scales. During the calibration period, $\mathrm{P} 8$ performed the worst of the three models on the hourly time step, on average, among the three performance statistics, ranking third in NSE and $\mathrm{R}^{2}$ and ranking second in PBIAS. At the daily time step, $\mathrm{P} 8$ ranked third in NSE, second in PBIAS, and first in $\mathrm{R}^{2}$, though very narrowly scored higher than the other models in $\mathrm{R}^{2}$.

Relative to the other models, the performance of P8 was the most consistent overall between the calibration and validation periods. P8 performed the best during the validation period on average among the three performance statistics, ranking first in the hourly and daily NSE and PBIAS performance statistics (table 6). However, P8 did rank third in hourly and daily $\mathrm{R}^{2}$. P8 outperformed its calibration statistics for hourly PBIAS and hourly NSE during the validation period, with satisfactory PBIAS ( -12 percent $< \pm 15$ percent) but still with a not satisfactory NSE $(-0.58<0.50)$. At the daily scale, the validated P8 model performance approached satisfactory levels, though it did not reach satisfactory thresholds of performance for NSE $(0.35<0.50)$ or $\mathrm{R}^{2}(0.44<0.60)$. P8 overpredicted observed flow (positive PBIAS) during the calibration period, but underpredicted observed flow (negative PBIAS) during the validation period. Relatively strong performance during the validation period indicates that the P8 model, once calibrated, may maintain reasonably robust results outside the calibration period.

For the HEC-HMS and P8 models, performance statistic rankings were averaged separately for NSE, PBIAS, and $\mathrm{R}^{2}$ across the calibration and validation periods, giving rankings for overall performance with consideration of the calibration and validation periods. This was done separately for the hourly and daily time steps. By using this rank-averaging approach for the hourly time step, the HEC-HMS model using the CN and SCS unit hydrograph methods ranked the highest, followed by P8, which was tied with the HEC-HMS initial and constant approach for second (table 7). For the daily time step, the HEC-HMS CN-based model and P8 were tied for the highest ranking, followed by the HEC-HMS initial and constantbased model. 
Alternatively, model performance may be rated according to performance during the validation period alone, which provides evidence of how each model, once calibrated for local conditions, performs during an independent period of climatic record. The validation period (using calibrated parameters without adjustment) demonstrates the unattended accuracy of the calibrated model and provides a measure of the expected confidence in forecasted results for future conditions. By using the validation period performance (table 7), the P8 model performed best for both hourly and daily time-steps followed by the HEC-HMS CN-based model and the HEC-HMS initial and constant-based model.

\section{Arid-Lands Hydrologic Model (AHYMO)}

The AHYMO is limited to 600 input points, and therefore is limited to simulating specific events rather than continuous time periods. Rather than using the performance statistics that are more suited for longer periods, the simulated events from AHYMO were evaluated by using the recommended performance measurement statistics in Moriasi and others (2015). These statistics include magnitude of peak discharge, the timing of peak discharge, the total storm runoff volume, and the duration of the event (tables 8 and 9). Five different rainfall-runoff events were simulated by using AHYMO, with one to three discharge peaks each (fig. 5). Observed peak hydrographs ranged in duration from 5 hours and 10 minutes (event 4, peak 1) to 13 hours and 35 minutes (event 4, peak 2) (table 9). This model was not calibrated in this study, so the simuation period was not separated into calibration and validation periods.

Among the five model run periods, the percent error of peak discharge ranged from -370 percent to 79 percent (average $=-115$ percent, standard deviation $=151$ percent), with the closest to zero being -15 percent (table 9). The percent error of total storm runoff volume ranged from -467 percent to 76 percent (average $=-141$ percent, standard deviation $=$ 165 percent), with the closest to zero being 33 percent. The negative average peak discharge and stormflow total runoff volume percent errors for the observed and simulated data indicate that the models tended to overpredict the observed discharge values, though this was not always the case, because the percent error was also positive for some events. The strength in AHYMO may be its ability to predict the timing and duration of the storm event, as well as its ability to match a similar recession curve shape, though this observation is subjective. The timing of peak flow between the simulated and observed data got as close as a single time step and averaged approximately 1 hour and 8 minutes difference. Based on a visual comparison, the hydrographs, including the recession curves, had a similar shape, which was quantitatively supported by the similar duration of events. The difference in duration of event got as low as 30 minutes (event 4, peak 1), equivalent to six time steps.

The model tended to overpredict stormflow magnitude and volume with the default parameters that were determined for use in the Albuquerque area. In future studies, the initial and constant loss could potentially be augmented to higher values to reduce the overestimation of discharge; however, a physical justification such as ground truthing would need to accompany the augmentation of these rates. The model's predictive accuracy may benefit from more field testing of the initial and constant loss rate parameter values. In addition, it is possible that the model would perform better on different sized watersheds, so testing of the model on smaller and larger gaged watersheds may be beneficial as well.

Table 8. Summarized model performance measures for the AHYMO model. A statistical summary is given across the five simulated AHYMO events.

[AHYMO, Arid-Lands Hydrologic Model. Basic summary statistics are displayed for the percent error or difference in various performance measures among the five simulated events. "Best" refers to the most desirable result obtained from the results for each performance measure. A perfect result for any performance measure in this table is zero. Therefore, the result closest to zero was chosen as the "Best" result.]

\begin{tabular}{lccccc}
\hline & Minimum & Maximum & Average & Standard deviation & Best \\
\hline $\begin{array}{l}\text { Peak discharge: Percent error } \\
\text { Timing of peak discharge }\end{array}$ & -370 & 79 & -115 & 151 & -15 \\
$\quad$ (hours:minutes): Difference & $0: 01$ & $5: 40$ & $1: 08$ & $1: 43$ & $0: 01$ \\
$\begin{array}{l}\text { Total storm runoff volume } \\
\quad \text { Percent error }\end{array}$ & -467 & 76 & -141 & 165 & 33 \\
$\begin{array}{l}\text { Duration of event (hours:minutes): } \\
\quad \text { Difference }\end{array}$ & $0: 30$ & $3: 22$ & $1: 52$ & $0: 59$ & $0: 30$ \\
\hline
\end{tabular}


Table 9. AHYMO performance measures by event.

[AHYMO, Arid-Lands Hydrologic Model; ft3/s cubic foot per second; $\mathrm{ft}^{3}$, cubic foot; acre-ft, acre-foot; dates are in month/day/year format]

\begin{tabular}{|c|c|c|c|c|c|c|c|c|c|}
\hline & \multicolumn{3}{|c|}{ Peak 1} & \multicolumn{3}{|c|}{ Peak 2} & \multicolumn{3}{|c|}{ Peak 3} \\
\hline & Simulated & Observed & $\begin{array}{l}\text { Percent } \\
\text { error, or } \\
\text { differ- } \\
\text { ence }\end{array}$ & Simulated & Observed & $\begin{array}{c}\text { Percent } \\
\text { error, or } \\
\text { difference }\end{array}$ & Simulated & Observed & $\begin{array}{l}\text { Percent } \\
\text { error, or } \\
\text { difference }\end{array}$ \\
\hline \multicolumn{10}{|c|}{ Event 1} \\
\hline Discharge (peak) (ft3/s) & 527 & 145 & -264 & & & & & & \\
\hline Timing (peak) & 5/11/2012 16:24 & $5 / 11 / 201216: 25$ & $0: 01$ & & & & & & \\
\hline Volume (ft3) & $1,427,220$ & 344,631 & -314 & & & & & & \\
\hline Volume (acre-ft) & 32.8 & 7.9 & -314.1 & & & & & & \\
\hline $\begin{array}{l}\text { Duration of event } \\
\text { (hours:minutes) }\end{array}$ & $10: 42$ & $7: 20$ & $3: 22$ & & & & & & \\
\hline \multicolumn{10}{|c|}{ Event 2} \\
\hline Discharge (peak) (ft3/s) & 12 & 18 & 33 & 62 & 128 & 52 & & & \\
\hline Timing (peak) & $7 / 2 / 201220: 35$ & $7 / 2 / 201223: 20$ & $2: 45$ & $7 / 3 / 201211: 25$ & 7/3/2012 17:05 & $5: 40$ & & & \\
\hline Volume ( $\left.\mathrm{ft}^{3}\right)$ & 52,080 & 102,594 & 49 & 257,610 & 386,886 & 33 & & & \\
\hline Volume (acre-ft) & 1.2 & 2.4 & 49.2 & 5.9 & 8.9 & 33.4 & & & \\
\hline $\begin{array}{l}\text { Duration of event } \\
\text { (hours:minutes) }\end{array}$ & 8:00 & $6: 30$ & $1: 30$ & $11: 05$ & $12: 05$ & $1: 00$ & & & \\
\hline \multicolumn{10}{|c|}{ Event 3} \\
\hline Discharge (peak) (ft3/s) & 141 & 30 & -370 & 231 & 132 & -75 & 79 & 33 & -140 \\
\hline Timing (peak) & $7 / 4 / 201322: 20$ & $7 / 4 / 201322: 30$ & $0: 10$ & $7 / 5 / 201316: 30$ & $7 / 5 / 201316: 23$ & $0: 07$ & 7/6/2013 0:50 & $7 / 6 / 20132: 20$ & $1: 30$ \\
\hline Volume ( $\left.\mathrm{ft}^{3}\right)$ & 543,720 & 174,510 & -212 & 569,580 & 272,679 & -109 & 947,430 & 491,085 & -93 \\
\hline Volume (acre-ft) & 12.5 & 4.0 & -211.6 & 13.1 & 6.3 & -108.9 & 21.8 & 11.3 & -92.9 \\
\hline $\begin{array}{l}\text { Duration of event } \\
\text { (hours:minutes) }\end{array}$ & $10: 45$ & $8: 05$ & $2: 40$ & $4: 00$ & $5: 10$ & $1: 10$ & $14: 50$ & $11: 30$ & $3: 20$ \\
\hline \multicolumn{10}{|c|}{ Event 4} \\
\hline Discharge (peak) (ft3/s) & 29 & 140 & 79 & 1,874 & 776 & -141 & & & \\
\hline Timing (peak) & $7 / 19 / 20136: 55$ & 7/19/2013 6:10 & $45: 00$ & 7/19/2013 16:40 & 7/19/2013 16:30 & $0: 10$ & & & \\
\hline Volume $\left(\mathrm{ft}^{3}\right)$ & 73,680 & 305,052 & 76 & $6,302,880$ & $1,111,440$ & -467 & & & \\
\hline Volume (acre-ft) & 1.7 & 7.0 & 75.8 & 144.7 & 25.5 & -467.1 & & & \\
\hline $\begin{array}{l}\text { Duration of event } \\
\text { (hours:minutes) }\end{array}$ & $5: 40$ & $5: 10$ & $0: 30$ & $12: 00$ & $13: 35$ & $1: 35$ & & & \\
\hline
\end{tabular}


Table 9. AHYMO performance measures by event.-Continued

[AHYMO, Arid-Lands Hydrologic Model; ft3/s cubic foot per second; $\mathrm{ft}^{3}$, cubic foot; acre-ft, acre-foot; dates are in month/day/year format]

\begin{tabular}{|c|c|c|c|c|c|c|c|c|c|}
\hline & \multicolumn{3}{|c|}{ Peak 1} & \multicolumn{3}{|c|}{ Peak 2} & \multicolumn{3}{|c|}{ Peak 3} \\
\hline & Simulated & Observed & $\begin{array}{c}\text { Percent } \\
\text { error, or } \\
\text { differ- } \\
\text { ence }\end{array}$ & Simulated & Observed & $\begin{array}{l}\text { Percent } \\
\text { error, or } \\
\text { difference }\end{array}$ & Simulated & Observed & $\begin{array}{l}\text { Percent } \\
\text { error, or } \\
\text { difference }\end{array}$ \\
\hline \multicolumn{10}{|c|}{ Event 5} \\
\hline Discharge (peak) $\left(\mathrm{ft}^{3} / \mathrm{s}\right)$ & 780 & 681 & -15 & 580 & 140 & -314 & & & \\
\hline Timing (peak) & 9/12/2013 11:55 & 9/12/2013 12:05 & $0: 10$ & 9/13/2013 19:40 & 9/13/2013 19:35 & $0: 05$ & & & \\
\hline Volume $\left(\mathrm{ft}^{3}\right)$ & $4,649,700$ & $2,064,876$ & -125 & $1,401,540$ & 399,342 & -251 & & & \\
\hline Volume (acre-ft) & 106.7 & 47.4 & -125.2 & 32.2 & 9.2 & -251.0 & & & \\
\hline $\begin{array}{l}\text { Duration of event } \\
\text { (hours:minutes) }\end{array}$ & $7: 40$ & $8: 35$ & $0: 55$ & $8: 40$ & $6: 00$ & $2: 40$ & & & \\
\hline
\end{tabular}



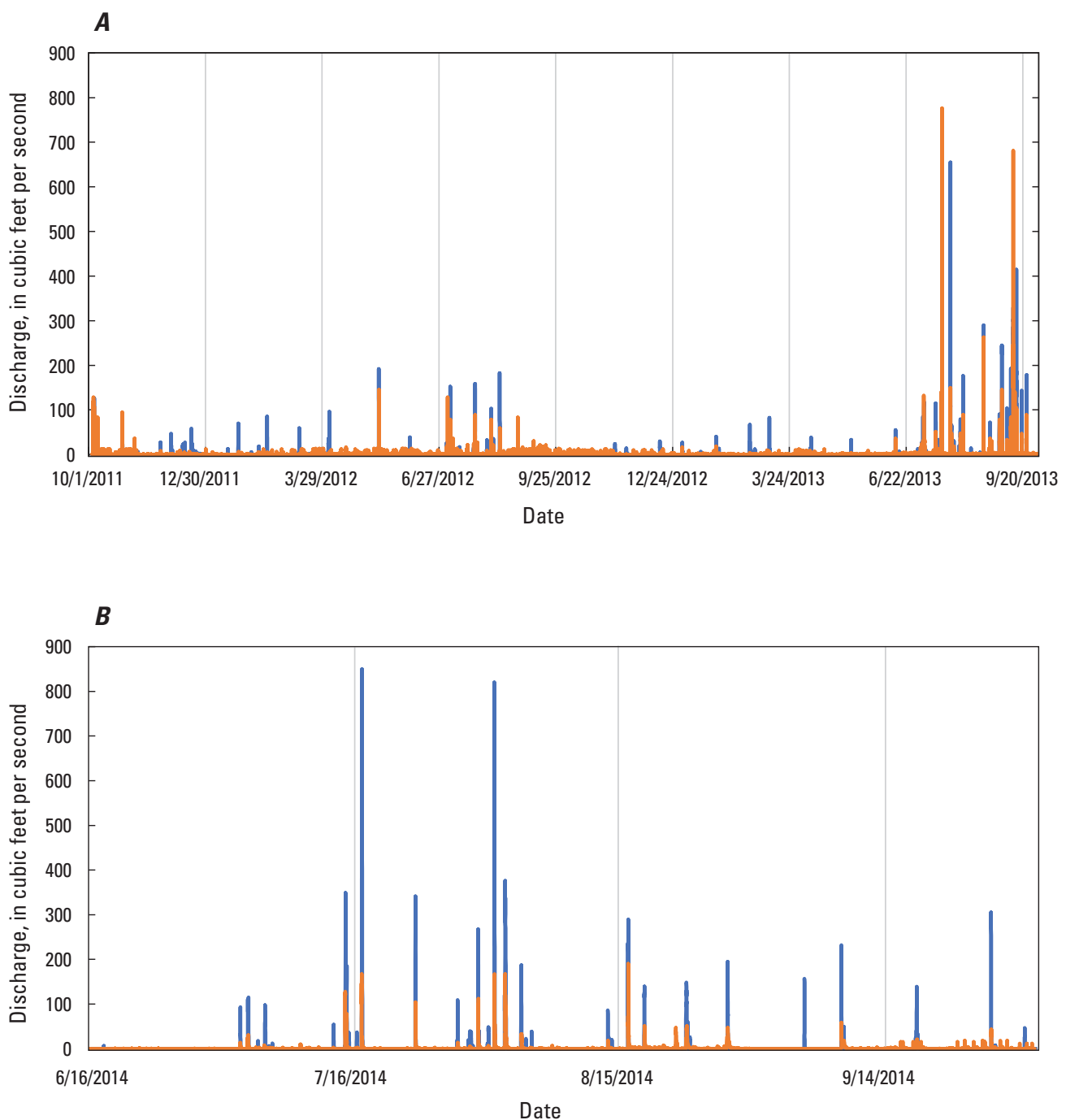

\section{EXPLANATION}

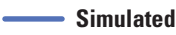

Figure 2. Discharge data observed at the Hahn Arroyo streamgage (USGS 08329840, Hahn Arroyo in Albuquerque, New Mexico; USGS, 2019) and simulated by using the Hydrologic Engineering Center Hydrologic Modeling System curve-number approach during the $A$, calibration period, and $B$, validation period. 

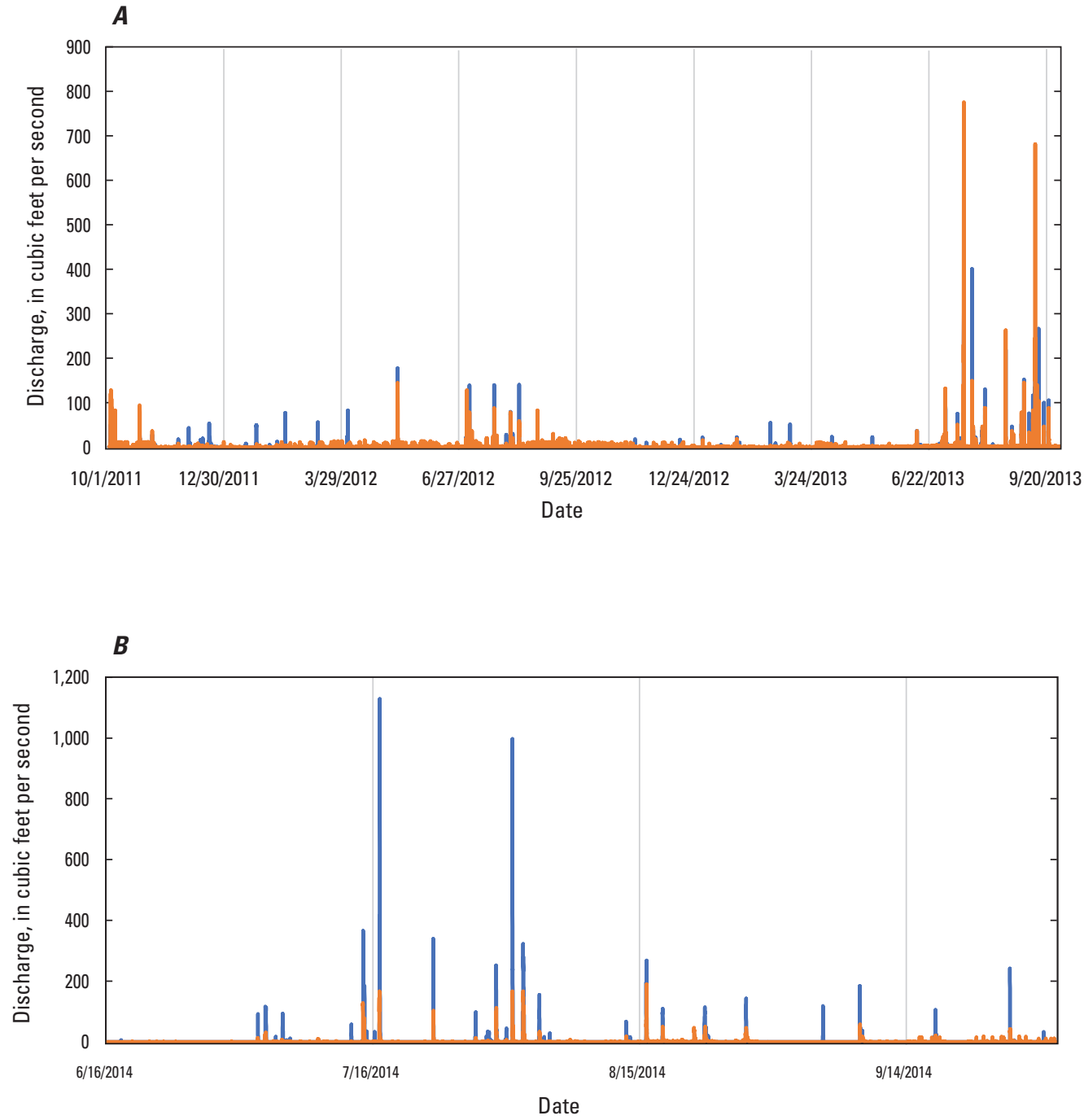

EXPLANATION

Simulated

Observed

Figure 3. Discharge data observed at the Hahn Arroyo streamgage (USGS 08329840, Hahn Arroyo in Albuquerque, New Mexico; USGS, 2019) and simulated by using the Hydrologic Engineering Center Hydrologic Modeling System initial and constant loss approach during the $A$, calibration period, and $B$, validation period. 

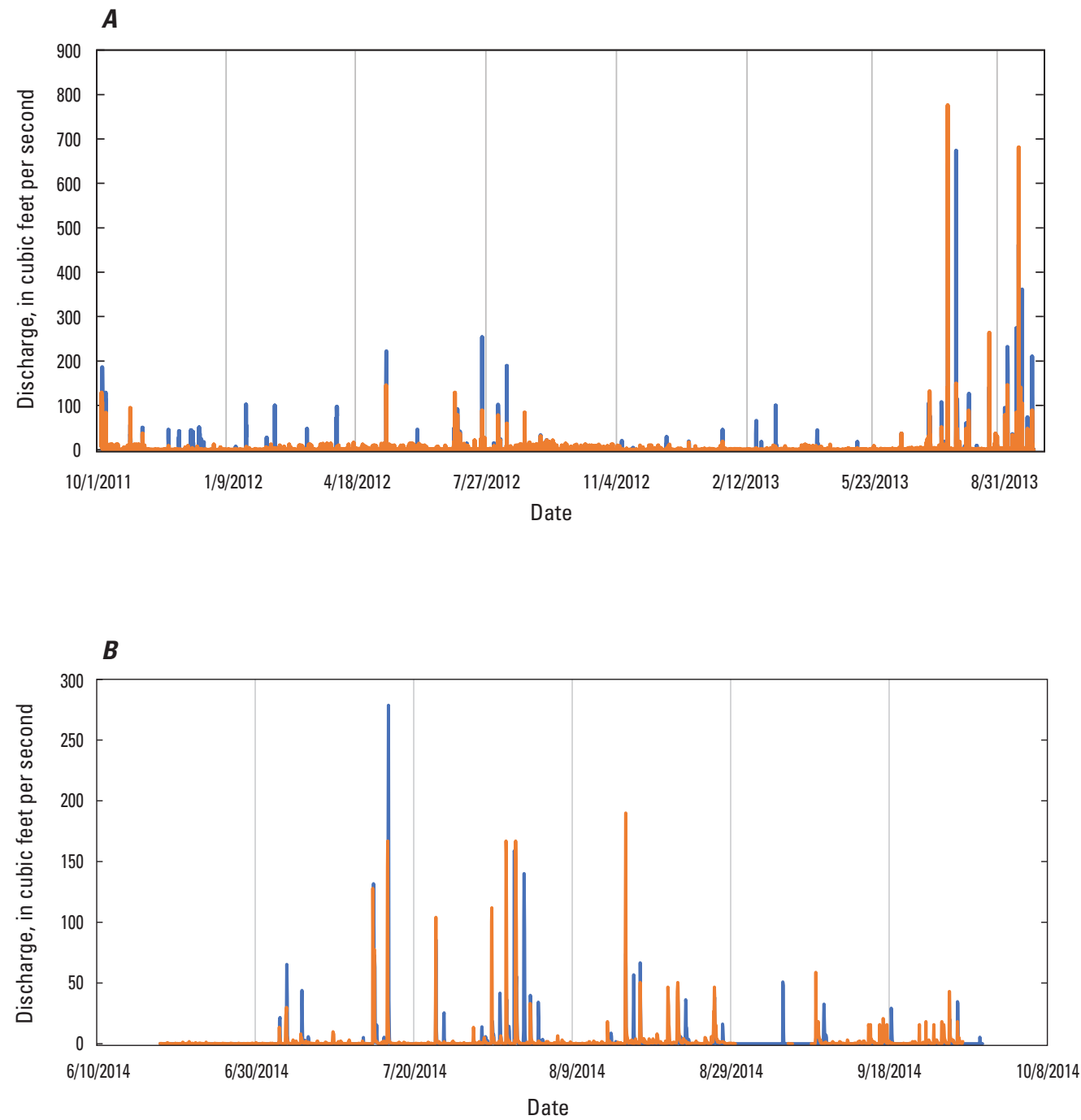

EXPLANATION

Simulated

Observed

Figure 4. Discharge data observed at the Hahn Arroyo streamgage (USGS 08329840, Hahn Arroyo in Albuquerque, New Mexico; USGS, 2019) and simulated by using the Program for Predicting Polluting Particle Passage through Pits, Puddles, and Ponds model during the $A$, calibration period, and $B$, validation period. 


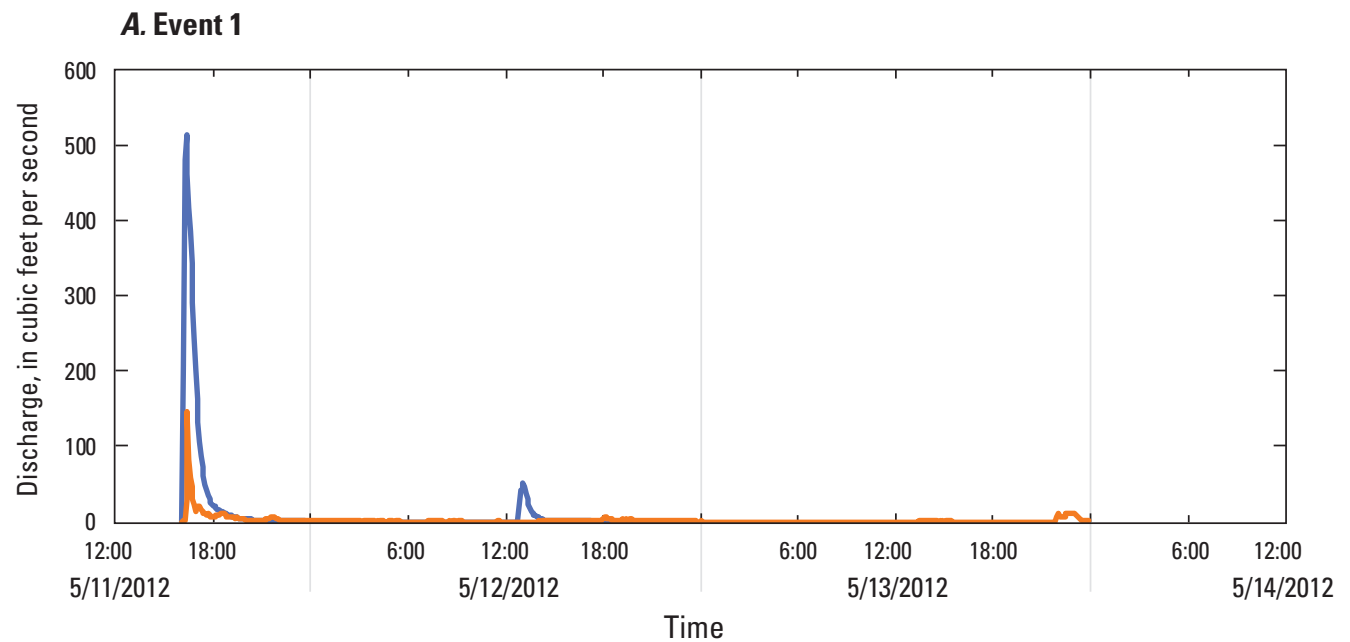

B. Event 2

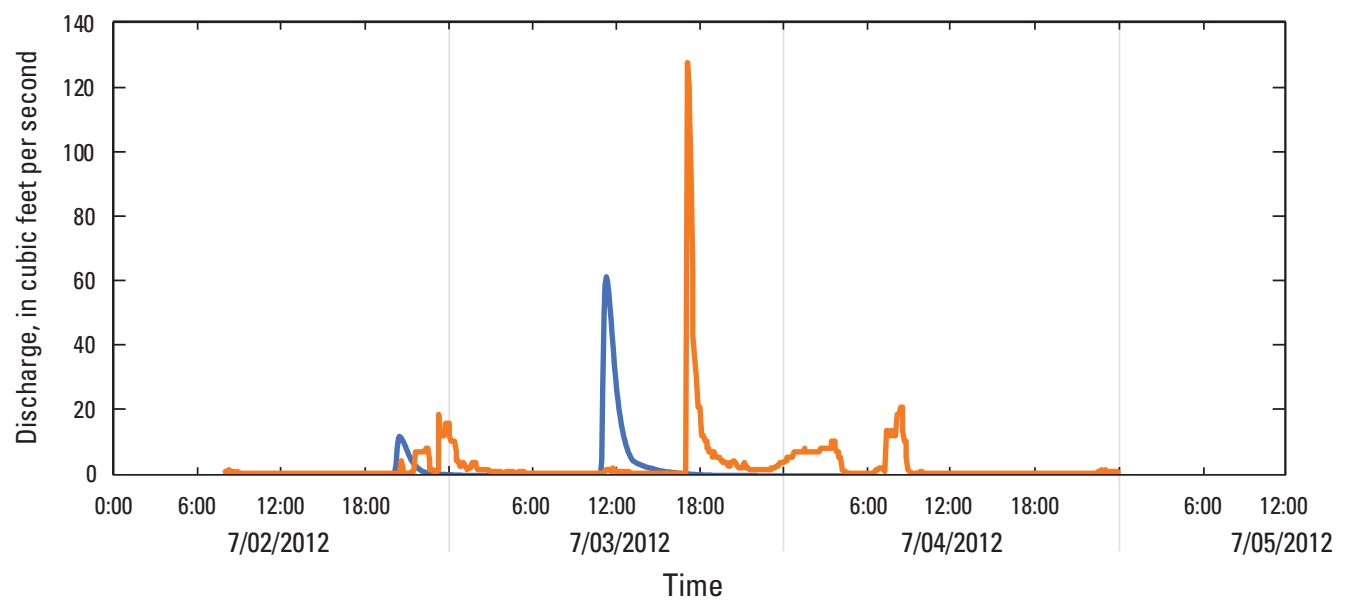

\section{Event 3}

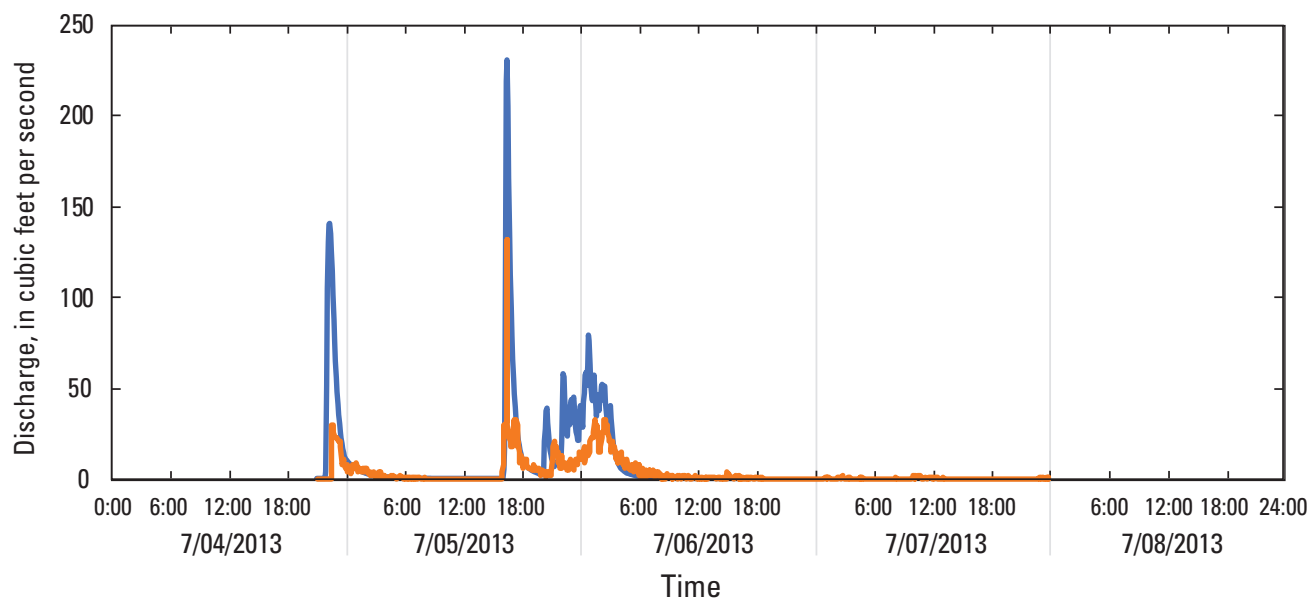

EXPLANATION

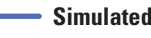

Observed

Figure 5. Discharge data observed at the Hahn Arroyo streamgage (USGS 08329840, Hahn Arroyo in Albuquerque, New Mexico; USGS, 2019) and simulated by using the Arid-Lands Hydrologic Model for five rainfall-runoff events (table 9). 

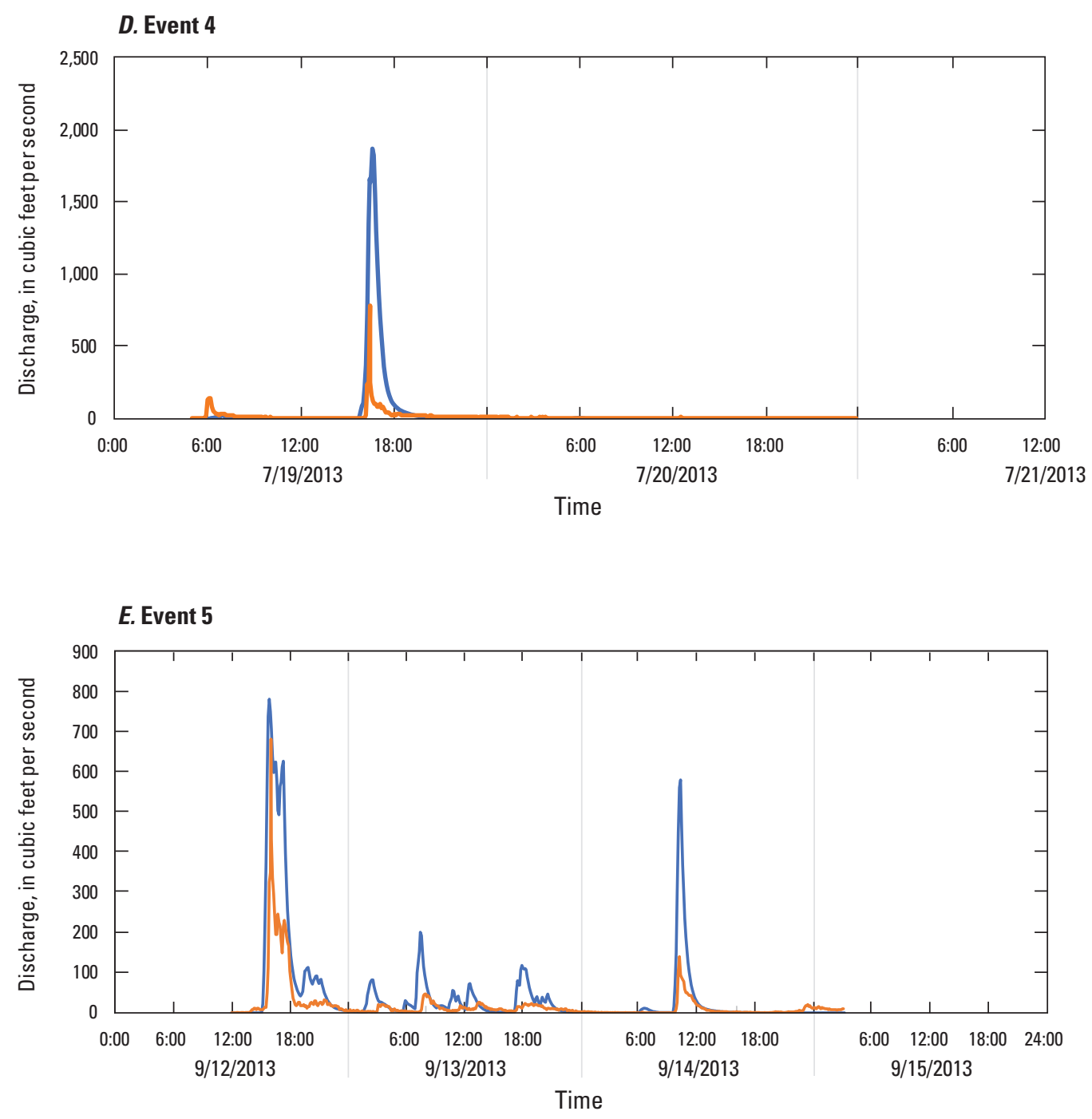

EXPLANATION

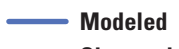

Observed

Figure 5. Discharge data observed at the Hahn Arroyo streamgage (USGS 08329840, Hahn Arroyo in Albuquerque, New Mexico; USGS, 2019) and simulated by using the Arid-Lands Hydrologic Model for five rainfall-runoff events (table 9).-Continued 


\section{Model Selection Considerations}

The following points may be considered when selecting a model for future applications or studies. The ultimate selection of one of these models for future study may depend on the availability of data, the intened use, desired accuracy for a given time step, and similarity of the study area to that of the one used in this study. Model users may benefit from considering their modeling expertise, as well as the allotted time to complete the study. The HEC-HMS and P8 models did not have satisfactory hourly performance from a quantitative standpoint when using standards determined by the literature. Both models performed better at the daily time scale and achieved marginally satisfactory performance overall considering multiple performance standards. Using the models in the Albuquerque urbanized area in a watershed similar in size to the Hahn Arroyo could produce undesirable results, particularly at the hourly time scale, though results may vary for larger time-steps, smaller or larger watersheds, or watersheds with different land-use conditions or different hydrologic conditions. This study was limited to the assessment of three models to facilitate a manageable scope that was directly relevant to the modeling needs of the $\mathrm{COA}$, rather than all potential applications of the models in the Albuquerque urbanized area. Further study may be required to assess the model performance capabilities in other modeling applications.

When the model performances were compared in relation to each other, the HEC-HMS model using the SCS-CN and SCS unit hydrograph methods ranked the highest when averaging the individual NSE, PBIAS, and $\mathrm{R}^{2}$ rankings together across the hourly calibration and validation periods, followed by P8, which was tied with the HEC-HMS initial and constant approach (table 7). For daily rankings using the same rankaveraging approach, the HEC-HMS model using the SCS-CN approach and the $\mathrm{P} 8$ model were tied for the highest ranking, followed by the HEC-HMS initial and constant approach. Alternatively, rating models by validation-period performance alone, which provides evidence of how each calibrated model performs during an independent period of climatic record, indicated that the P8 model performed best for both hourly and daily time-steps followed by the HEC-HMS CN-based model and the HEC-HMS initial and constant-based model.

Direct comparison of the HEC-HMS and P8 models to AHYMO is difficult, given the different performance assessment criteria used to assess these models separately in this study. The AHYMO results generally lacked precision, given the wide range in the performance assessment values in peak discharge percent error, difference in timing of peak discharge, total runoff volume percent error, and difference in duration of event. For some events, however, the AHYMO results were fairly accurate. When assessing simulated and observed data, AHYMO estimated the timing of peak discharge within one time-step and measured percent error within -15 percent for peak discharge between simulated and observed data. AHYMO was also a good predictor of the timing of storm runoff and the shape of the hydrograph. Given the flashy behavior of the precipitation events and response hydrographs in the Albuquerque area, the 1-hour intervals used in P8 may not be appropriate for simulating the timing of peak stormflow discharge or the shape of the hydrograph. AHYMO and HECHMS operate at a temporal resolution more suitable for the stormflow events experienced in Albuquerque than P8.

The equations used in HEC-HMS and P8 were not empirically derived in conditions specific to Albuquerque, nor were they derived to intentionally represent the physical or hydrologic conditions specific to Albuquerque. The widespread use of these equations in the modeling community, however, has led them to be accepted for general surface-water modeling applications. The AHYMO model was developed to be used specifically in Albuquerque or other areas of New Mexico and has been generally accepted by local professionals. The usability, or ease of use, of any of the three models may be subjective to the user, and selection among these models may also depend on available data and the allotted time to set up and run the models. Details on ease of use and data requirements were discussed in the "Model Data Requirement Comparison" section of this report.

\section{Summary}

In order to comply with a current U.S. Environmental Protection Agency watershed-based National Pollutant Discharge Elimination System permit, the City of Albuquerque required a better understanding of the rainfall-runoff processes in its small urban watersheds. That requirement prompted the initiation of the assessment of three existing watershed models that were developed to simulate those processes. That study, described in this report, had the sole intent of comparing the performance of the three models, including the currently used Arid-Lands Hydrologic Model (AHYMO), to inform the stormflow-management decisions of the local government entities. Additionally, results of this study could help inform model users who have interest in simulating storm runoff in similar urban areas throughout the United States.

The rainfall-runoff modeling spatial domain is the Hahn Arroyo watershed, which is in the northeast quadrant of Albuquerque. The Hahn Arroyo watershed was selected as the study watershed largely due to the duration and quality of available continuous discharge data and precipitation data. The Hahn Arroyo watershed is also of intermediate size relative to other urban watersheds within the Albuquerque area, contains the drainage infrastructure commonly found elsewhere in Albuquerque, and has a representative mix of commercial, residential, and other land-use conditions for much of the Albuquerque urbanized area.

Input data requirements for the three models are relatively similar, though their input format does vary. The usability, or ease-of-use, of the three models may be subjective to the user, and selection among these models may also depend 
on available data and the allotted time to set up and run the models. The Hydrologic Engineering Center Hydrologic Modeling System (HEC-HMS) offers users the most simplistic data input interface and automates the calculation of weighted precipitation data. The geospatial data requirements for the derivation of the model parameters vary among the three models, and the Program for Predicting Polluting Particle Passage Through Pits, Puddles, and Ponds (P8) has the most extensive geospatial data and analysis requirements. Users may find the HEC-HMS graphical user interface to be the most user friendly, though some may prefer the simple one-file input and command line format of AHYMO or the straightforward appearance of the $\mathrm{P} 8$ graphical user interface.

In this study, two different model setups were used in HEC-HMS: one that used the Soil Conservation Service (SCS) curve number $(\mathrm{CN})$ loss method and the SCS unit hydrograph transform method, and a second that used the initial and constant loss method and SCS unit hydrograph transform method. The default methods were used in P8, and method recommendations from the Albuquerque Development Process Manual were used in AHYMO. The equations used in HEC-HMS and P8 were not empirically derived for conditions specific to Albuquerque, nor were they derived to intentionally represent the physical or hydrologic conditions specific to Albuquerque. The widespread use of these equations in the modeling community has led them to be accepted for general surface-water modeling applications. The AHYMO model was developed to be used specifically in Albuquerque or other areas of New Mexico and has been generally accepted by local professionals. Given the flashy - high intensity and short durationbehavior of the precipitation events and response hydrographs in the Albuquerque area, the 1-hour intervals used in P8 may not be appropriate for simulating the timing of peak stormflow discharge or the shape of the hydrograph. AHYMO and HECHMS operate at a temporal resolution more suitable for the stormflow events experienced in Albuquerque than P8.

The HEC-HMS and P8 models did not have satisfactory hourly performance from a quantitative standpoint when using standards determined by the literature. Both models performed better at the daily time scale and achieved marginally satisfactory performance overall considering multiple performance standards. Using the models in the Albuquerque urbanized area in a watershed similar in size to the Hahn Arroyo could produce undesirable results, particularly at the hourly time scale, though results may vary for larger time-steps, smaller or larger watersheds, or watersheds with different land-use conditions or different hydrologic conditions.

When overall model performances were compared, the HEC-HMS model using the SCS-CN unit hydrograph approach ranked the highest when averaging the individual Nash-Sutcliffe model efficiency coefficient, percent bias, and coefficient of determination rankings together across the hourly calibration and validation periods, followed by P8, which was tied with the HEC-HMS initial and constant approach. For daily rankings using the same rank-averaging approach, the HEC-HMS CN-based model and P8 were tied for the highest ranking, followed by the HEC-HMS initial and constant approach. Alternatively, focusing on the validation period alone as an indicator of the unattended accuracy of the calibrated model, the P8 model performed best for both hourly and daily time-steps followed by the HEC-HMS CN-based model and the HEC-HMS initial and constant-based model.

Direct comparison of the HEC-HMS and P8 models to AHYMO is difficult, given the different performance assessment criteria used to assess these models separately in this study, as recommended by the literature. The AHYMO results generally lacked precision, given the wide range in the performance assessment values in percent error in peak discharge, difference in timing of peak discharge, percent error in total runoff volume, and difference in duration of event. For some events, however, the AHYMO results were fairly accurate, and AHYMO was likely a good predictor of the timing of storm runoff and the shape of the hydrograph.

This study was limited to the assessment of three models to facilitate a manageable scope that was directly relevant to the modeling needs of the COA, rather than all potential applications of the models in the Albuquerque urbanized area. Further study may be required to assess the model performance capabilities in other modeling applications. The ultimate selection of one of these models for future study may depend on the availability of data, the intended use, desired accuracy for a given time step, and similarity of the study area to that of the one used in this study. Model users may benefit from considering their modeling expertise, as well as the allotted time to complete the study.

\section{References Cited}

\author{
Albuquerque Metropolitan Arroyo Flood Control Authority \\ [AMAFCA], 2018, Migrating from AHYMO'97 to HEC- \\ HMS (and USEPA SWMM): prepared by Occam Engineers, \\ Inc., accessed January 2020 at https://amafca.org/ \\ downloadabledata/STATE\%20OF\%20PRACTICE\%20 \\ FOR\%20HYDROLOGY\%20White\%20Paper\%20 \\ Complete\%206.11.18.pdf.
}

Albuquerque Metropolitan Arroyo Flood Control Authority [AMAFCA], 2019, Maintenance responsibilities for drainage facilities in the Albuquerque metropolitan area, accessed August 2019 at https://www.amafca.org/ documents/Maintenance_Map.pdf.

Anderson, C.E., and Heggen, R.J., 1991, A comparison of a gaged urban watershed and computer modeling using HYMO, in Inspiration-Come to the headwaters: Proceedings of the Fifteenth Annual Conference of the Association of State Floodplain Managers, Denver, Colorado, p. 107-112. 
City of Albuquerque [COA], 2018a, Download GIS data: City of Albuquerque database, accessed September 2018 at https://www.cabq.gov/gis/geographic-information-systemsdata. [Database moved by time of publication; accessed August 28, 2019, at https://data-cabq.opendata.arcgis.com/.]

City of Albuquerque [COA], 2018b, AHYMO computer program user's manual, version AHYMO-S4-R2: Albuquerque, N.M., City of Albuqueque, Hydrology Section, 175 p., accessed July 2019 at http://documents.cabq.gov/planning/ DevelopmentReviewServices/Hydro-AHYMO-S4\%20 R2\%20User\%20Manual-10-24-18.pdf.

City of Albuquerque [COA], 2019, Chapter 22-Drainage, flood control and erosion control, in Volume II-Design criteria, Albuquerque Development Process Manual: Albuquerque, N.M., City of Albuqueque, Hydrology Section, accessed July 2019 at https://www.cabq.gov/ planning/development-review-services/hydrology-section.

Doherty, J., 2018a, PEST Model-independent Parameter Estimation User Manual Part 1-PEST, SENSAN and Global Optimisers, 7th ed.: Watermark Numerical Computing, $364 \mathrm{p}$.

Doherty, J., 2018b, PEST Model-independent Parameter Estimation User Manual Part 2-PEST Utility Support Software, 7th ed.: Watermark Numerical Computing, $257 \mathrm{p}$.

Esri, 2018, ArcMap—Release 10.6.1: Redlands, Calif., Environmental Systems Research Institute.

Harmel, R.D., Baffaut, C., and Douglas-Mankin, K., 2018, Review and development of ASABE Engineering Practice 621-Guidelines for calibrating, validating, and evaluating hydrologic and water quality models: Transactions of the ASABE, v. 61, no. 4, p. 1393-1401, accessed February 10, 2020, at https://doi.org/10.13031/trans. 12806.

Harmel, R.D., Smith, P.K., Migliaccio, K.W., Chaubey, I., Douglas-Mankin, K.R., Benham, B., Shukla, S., MuñozCarpena, R., and Robson, B.J., 2014, Evaluating, interpreting, and communicating performance of hydrologic/ water quality models considering intended use-A review and recommendations: Environmental Modelling \& Software, v. 57, p. 40-51, accessed February 10, 2020, at https://doi.org/10.1016/j.envsoft.2014.02.013.

Hawkins, R.H., Hjelmfelt, A.T., Jr., and Zevenbergen, A.W., 1985, Runoff probability, storm depth, and curve numbers: Journal of Irrigation and Drainage Engineering, v. 111, no. 4, p. 330-340. [Also available at https://doi.org/10.1061/ (ASCE)0733-9437(1985)111:4(330).]

IEP, Inc., 1990, P8 Urban Catchment Model-User's manual, version 1.1: Prepared for Narragansett Bay Project, 118 p., accessed January 18, 2018, at http://www.wwwalker.net/p8/ p8_users_manual.pdf.
Knutilla, R.L., and Veenhuis, J.E., 1994, Computer simulation of storm runoff for three watersheds in Albuquerque, New Mexico: U.S. Geological Survey Water-Resources Investigations Report 94-4143, 61 p.

Mishra, S.K., Jain, M.K., Suresh Babu, P., Venugopal, K., and Kaliappan, S., 2008, Comparison of AMC-dependent $\mathrm{CN}$-conversion formulae: Water Resources Management, v. 22, no. 10, p. 1409-1420, accessed April 5, 2019, at https://doi.org/10.1007/s11269-007-9233-5.

Moriasi, D.N., Zeckoski, R.W., Arnold, J.G., Baffaut, C., Malone, R.W., Daggupati, P., Guzman, J.A., Saraswat, D., Yuan, Y., Wilson, B.N., Shirmohammadi, A., and Douglas-Mankin, K.R., 2015, Hydrologic and water quality models - Key calibration and validation topics: Transactions of the ASABE, v. 58, no. 6, p. 1609-1618, accessed August 17, 2017, at https://doi.org/10.13031/ trans.58.11075.

National Oceanic and Atmospheric Administration [NOAA], 2019, NowData-NOAA Online Weather Data, accessed April 5, 2019, at https://www.nws.noaa.gov/climate.php/ xmaxis.php $\% 3$ fwfo=abq.

Natural Resources Conservation Service [NRCS], 1986, Urban hydrology for small watersheds: Washington, D.C., Natural Resources Conservation Service, U.S. Department of Agriculture, Technical Release 55.

Parece, T.E., and Campbell, J.B., 2015, Identifying urban watershed boundaries and area, Fairfax County, Virginia: Photogrammetric Engineering and Remote Sensing, accessed February, 10, 2020, at https://doi.org/10.14358/ PERS.81.5.365.

Schoener, G., 2010, Comparison of AHYMO and HEC-HMS for runoff modeling in New Mexico urban watersheds: Albuquerque, University of New Mexico, M.S. thesis.

Shephard, Z.M., and Douglas-Mankin, K.R., 2020, Input and output data used to compare storm runoff models for a small watershed in an urban metropolitan area, Albuquerque, New Mexico: U.S. Geological Survey data release, https://doi.org/10.5066/P930WKCH.

Sobhani, G., 1975, A review of selected small watershed design methods for possible adoption to Iranian conditions: Logan, Utah, Utah State University, M.S. thesis.

Soil Survey Staff, Natural Resources Conservation Service, U.S. Department of Agriculture, 2018, Web Soil Survey: Natural Resources Conservation Service, U.S. Department of Agriculture, accessed August 2018 at https://websoilsurvey.sc.egov.usda.gov/. 
Storms, E.F., Oelsner, G.P., Locke, E.A., Stevens, M.R., and Romero, O.C., 2015, Summary of urban stormwater quality in Albuquerque, New Mexico, 2003-12: U.S. Geological Survey Scientific Investigations Report 2015-5006, 48 p. [Also available at https://doi.org/10.3133/sir20155006.]

Southern Sandoval County Arroyo Flood Control Authority [SSCAFCA], 2009, Development Process Manual: Section 2, Hydrology, 110 p., accessed July 2019 at https://www.sscafca.org/development/documents/DPM/ DPM_4_2010/DPM_Section2_Hydrology.pdf.

Thiessen, A.H., 1911, Precipitation for large areas: Monthly Weather Review, v. 39, p. 1082-1084.

U.S. Army Corps of Engineers, [USACE], 2000, Hydrologic Modeling System-HEC-HMS, Technical Reference Manual CPD-74B: Davis, Calif., U.S. Army Corps of Engineers, Hydrologic Engineering Center, 155 p.

U.S. Army Corps of Engineers, [USACE], 2016, Hydrologic Modeling System HEC-HMS, Quick Start Guide, v. 4.2 CPD-74D: Davis, Calif., U.S. Army Corps of Engineers, Hydrologic Engineering Center, 56 p.

U.S. Army Corps of Engineers, [USACE], 2017a, Hydrologic Modeling System HEC-HMS, version 4.2.1, accessed February 6, 2020, at https://www.hec.usace.army.mil/ software/hec-hms/downloads.aspx.

U.S. Army Corps of Engineers, [USACE], 2017b, Geospatial Hydrologic Modeling Extension (HECGeoHMS), version 10.2, accessed February 6, 2020, at https://www.hec.usace.army.mil/software/hec-geohms/.

U.S. Census Bureau, 2017, 2013-2017 American community survey 5-year estimates: U.S. Census Bureau, accessed April 26, 2019, at https://www.census.gov/programssurveys/acs/?intcmp=serp.

U.S. Census Bureau, 2018, QuickFacts-Albuquerque city, New Mexico: U.S. Census Bureau, accessed August 22, 2019, at https://www.census.gov/quickfacts/ albuquerquecitynewmexico.
U.S. Environmental Protection Agency [EPA], 2019, National Pollutant Discharge Elimination System (NPDES), accessed April 20, 2019, at https://www.epa.gov/laws-regulations/ history-clean-water-act.

U.S. Geological Survey [USGS], 2019, USGS water data for the Nation: U.S. Geological Survey National Water Information System database, accessed May 17, 2019, at https://doi.org/10.5066/F7P55KJN.

Veenhuis, J.E., 2003, Municipal stormwater sampling program, metropolitan area, Albuquerque, New MexicoSummary of sampling, 1992-2002: U.S. Geological Survey Fact Sheet 005-03, accessed January 2014 at https://pubs.usgs.gov/fs/2003/0005/report.pdf.

Walker, W.W., 1990, P8 Urban Catchment Model—Program documentation, DOS version 1.1: prepared for IEP, Inc., and Narragansett Bay Project, October 1990, 73 p., 5 app., accessed January 18, 2018, at http://www.wwwalker.net/p8/ p8v1doc.pdf.

Walker, W.W., 1997, Documentation for P8, version 2.0: prepared for Wisconsin Department of Natural Resources and Minnesota Pollution Control Agency, 6 p., accessed January 18, 2018, at http://www.wwwalker.net/p8/p8v2.pdf.

Walker, W.W., and Walker, J.D., 2017, P8 Urban Catchment Model homepage, accessed January 18, 2018, at http://www.wwwalker.net/p8.

Westenbroek, S.M., Doherty, J., Walker, J.F., Kelson, V.A., Hunt, R.J., and Cera, T.B., 2012, Approaches in highly parameterized inversion: TSPROC, a general time-series processor to assist in model calibration and result summarization: U.S. Geological Survey Techniques and Methods, book 7, chap. C7, 79 p., 3 apps., accessed October, 26, 2018, at https://pubs.usgs.gov/tm/tm7c7.

Williams, J.R., and Hann, R.W., 1973, HYMO: Problemoriented computer language for hydrologic modeling, user's manual: U.S. Department of Agriculture, Agricultural Research Service, ARS-S-9. 
For more information about this publication, contact Director, New Mexico Water Science Center U.S. Geological Survey 6700 Edith Blvd NE

Albuquerque, New Mexico 87113

For additional information, visit https://www.usgs.gov/centers/nm-water Publishing support provided by Lafayette Publishing Service Center 
